\title{
CERÁMICAS HELENÍSTICAS DE RELIEVES EN LA ALCUDIA (ELCHE, ALICANTE)
}

\author{
GABRIEL LARA VIVES \\ Universidad de Alicante*
}

\begin{abstract}
Analizamos la presencia de cerámicas helenísticas de relieves en La Alcudia de Elche, cuya cronología remite a momentos finales del siglo ll o siglo I a.C. Del mismo modo, revisamos las circunstancias que provocan su aparición, hasta el punto de constituir uno de los conjuntos de este tipo de cerámicas más destacados del levante peninsular.
\end{abstract}

In this paper we analyse an important assemblage of Hellenistic pottery (2nd - 1st century B.C.) recovered in the ancient site of La Alcudia (Elche, Alicante, Spain). We reconsider the circumstances in which the pieces appeared, their morphology and characteristics. We also explain their role in the Romanization process of the south-eastern conventus Carthaginensis.

La formación de la colección de materiales arqueológicos que da cuerpo al "Museo Monográfico de La Alcudia" es el resultado de las excavaciones realizadas durante más de seis décadas en el yacimiento por la familia Ramos $^{1}$, y en ella podemos encontrar elementos propios de momentos finales de la Prehistoria hasta otros correspondientes a época emiral. La presencia de un conjunto de cerámicas de relieves entre estos materiales suscitó la elaboración del presente estudio.

Los cuencos con relieves, también denominados "cuencos megáricos"2, son unas producciones cerámicas fabricadas en época helenística a partir de moldes realizados con punzones, en los que la arcilla se presionaba para conseguir unas paredes delgadas. El borde se realizaba con arcilla estirada, uniéndolo al cuerpo y procediendo posteriormente al torneado para alisar la parte interna. Las formas más abundantes son diversas variantes de cuenco o copa, aunque se observa bastante versatilidad en la creación de otros tipos mediante la adición de asas, pies altos y otros elementos (Laumonier, 1977, 4). Este tipo de cerámica nace como sucedáneo de la vajilla de metal, por lo que existe gran dificultad para encontrar el original y la copia, aunque existen evidencias del mismo tipo en las cerámicas producidas en Cales, ya que en este lugar se producían copas con omphalos decoradas con carreras de carros similares a las realizadas en metal (Laumonier, 1977, 6; Siebert, 1980, 55). Destacan en la producción de las cerámicas de relieves varios aspectos, como son la importancia que alcanza el volumen de la masa documental, sólo comparable con el éxito que alcanza la cerámica "campaniense", la amplitud geográfica de su área de distribución ${ }^{3}$ y la circunstancia de que a pesar de la unidad de género que muestra el conjunto, el producto se revela como complejo por su versatilidad, pues aunque se trata de piezas de vajilla utilitaria y común, imitan vajilla de lujo con una calidad extraordinariamente variable (Siebert, 1980, 56).

El estudio de las piezas existentes en La Alcudia encuentra como precedente una serie de aproximaciones descriptivas donde se

\footnotetext{
Agradecemos las facilidades proporcionadas por la Fundación Universitaria de Investigación Arqueológica "La Alcudia" para completar este estudio,que se incluye en el proyecto BHA 2002-02028, del Ministerio de Ciencia y Tecnología.

1 A este conjunto de materiales se añadieron los pertenecientes a la Colección Ibarra (Ramos Fernández, 2003, 146) hasta el punto de que piezas procedentes de excavaciones en otros emplazamientos, como el Portus Ilicitanus o la Villa de Algorós se exponen junto a otras de La Alcudia.

${ }^{2}$ O. Benndorf, uno de los primeros en interesarse por estos vasos, creyó que se fabricaban en Megara (Griechische und sizilianische Vasenbilder III, 1883, 118) y su error ha sido consagrado por el uso en la terminología arqueológica.

${ }^{3}$ Desde Rusia meridional a las costas de África y de España hasta Afganistán (Siebert, 1980, 56).
} 
detallan fundamentalmente las características de la decoración y de la pasta, sin profundizar más allá de la adscripción tipológica ${ }^{4}$ y proporcionando una cronologia global a los materiales en función del contexto cerámico que se identificaba durante su extracción. A pesar de una tentativa de estudio global de la cerámica ibérica del yacimiento (Ramos Folqués, 1990) y de los tipos importados que aparecían junto a ella, la cerámica de relieves existente no ha sido analizada de forma exhaustiva y bajo criterios especificos ${ }^{5}$, circunstancia que ha propiciado un relativo desconocimiento de su existencia en estudios que han intentado reflejar un panorama general de las importaciones en el sureste de Hispania durante la época tardo-republicana ${ }^{6}$.

El conjunto existente en los fondos del Museo Monográfico de "La Alcudia" está compuesto por un total de 46 fragmentos: 22 fragmentos de borde, 9 fragmentos de base y 15 fragmentos de pared. Todas estas piezas pueden adscribirse a un número máximo de 31 cuencos distintos, identificación que se ha realizado tras analizar las características de todos los fragmentos existentes. Incluimos en el presente estudio dos fragmentos de punzón - molde procedentes de las excavaciones realizadas en el "templo ibérico" ubicado bajo la "basílica paleocristiana" (Ramos Fernández, 1995), debido a que los motivos que componen su decoración pertenecen al repertorio decorativo habitual de estas producciones. En cuanto a la procedencia de las piezas, de la mayoría de ellas sólo tenemos constancia de su habitual inclusión dentro del "nivel E", también denominado "nivel ibérico ll" o "ibéricopúnico"7, circunstancia que debido a la cronología general de los materiales aparecidos debería afinarse para ofrecer unos datos acordes con la información que disponemos de otros yacimientos en cronologías similares.

\section{CATÁLOGO}

\section{$N^{\circ}$ INV: LA-499}

FORMA: fragmento de borde.

DESCRIPCIÓN: fragmento de borde de un cuenco no reconstruible (Fig. 1,1). La decoración presenta, tras una franja lisa, la sucesión de una serie de motivos poco definidos, tal vez capullos vegetales, aunque por su aspecto podría tratarse con mayores probablidades de un friso de ovas y dardos. Bajo esta decoración encontramos un nuevo campo decorado con otros motivos indeterminados debido al estado de la pieza. Debido al aspecto indeterminado de su decoración resulta complicado atribuir a uno u otro taller, aunque probablemente nos encontremos con un cuenco del taller del monograma. $13 \mathrm{~cm}$ de diámetro.
BARNIZ: de color negro mate tanto en la superficie interna como en la externa.

PASTA: de color grisáceo con desgrasantes finos de origen micáceo, algunos con destellos plateados.

BIBLIOGRAFÍA: Inédito.

No INV: LA-941

FORMA: fragmento de borde.

DESCRIPCIÓN: borde de tipo entrante, con una franja lisa en su zona más próxima, a la que sucede otra con rosetas de ocho pétalos y una serie de $S$ acostadas (Fig. 1,2). Presenta dos tipos de motivos muy frecuentes, de difícil diferenciación por lo generalizado de su reproducción sobre los cuencos, encontrándolos tanto en las producciones del taller de $\mathrm{Me}$ némakhos como en las del taller que firma con un monograma, aunque debido a las similitudes que presentan las rosetas estrelladas que muestra la pieza con las que suelen realizarse en el taller del monograma, consideramos que es probable que pertenezcan a éste. $12 \mathrm{~cm}$ de diámetro. BARNIZ: en el interior el barniz oscila entre el marrón oscuro y el negro con reflejo metálico en la zona próxima al borde hasta el castaño rojizo predominante en el resto de la superficie interna. En la zona externa, se prolonga el color del interior del borde hasta la segunda banda decorada, siendo el resto de la superficie de la pieza de color rojizo.

PASTA: anaranjada, con desgrasantes micáceos muy finos. BIBLIOGRAFÍA: Laumonier, 1962, 43-47, Pt. VI.; Ramos Folqués, 1990, 129, lám. 36.

No INV: LA-942

FORMA: fragmento de borde y pared.

DESCRIPCIÓN: dos fragmentos que forman parte de la misma pieza, no reconstruible (Fig. 1,3). Se trata de un cuenco con el borde ligeramente entrante, decorado en la zona próxima al borde con una serie de rosetas de siete pétalos; bajo éstas se establece una zona decorada con una serie de volutas vegetales, entre las que se observan grupos de puntos. A continuación se aprecia un elemento que

4 Sirven como ejemplo las publicaciones en las que se mencionan como "vasos de Megara" o "cerámica de Megara" (Ramos Folqués, 1962; 1990), adscrita generalmente al "nivel E" (entre otras publicaciones, Ramos Fernández, 1975; Ramos Folqués y Ramos Fernández, 1976).

${ }^{5}$ Fruto del trabajo de especialistas como A. Laumonier, que en sus trabajos proporcionaba noticias de la presencia de fragmentos de cuencos en diversos puntos de la costa mediterránea española, aunque sólo publica varias fotografías debido a que centra su análisis en los motivos decorativos (Laumonier, 1962; 1977, 4). Sin embargo, este estudio es heredero de obras como: Ramos Folqués, 1956; Fernández de Avilés, 1957, 48 a 54, donde se presentan 26 fragmentos. Será en otros trabajos donde se plantee de forma breve la existencia de este tipo cerámico, como por ejemplo, en Ramos Fernández, 1974, 73.

${ }^{6}$ Asi vemos que Beltrán (Beltrán, 1990,61) refleja hallazgos en Cartagena y Elda, pero no señala la presencia del conjunto procedente de La Alcudia; o como J. Pérez Ballester (Pérez, $1994 ; 353$ ), revela conocer la existencia de un conjunto de al menos treinta piezas. Tenemos noticias de que existe un estudio de estos cuencos en prensa, por lo que definitivamente se esclarecerá el panorama en lo referente a la presencia de estas producciones cerámicas en La Alcudia (Cabrera, 2004).

7 Entre otros; ver Ramos Fernández, 1975, 125-146; Ramos Folqués y Ramos Fernández, 1976, 17-19. 

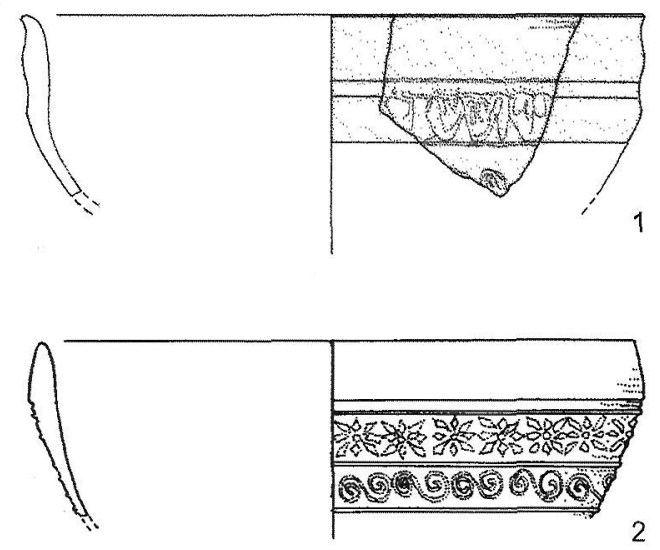

2

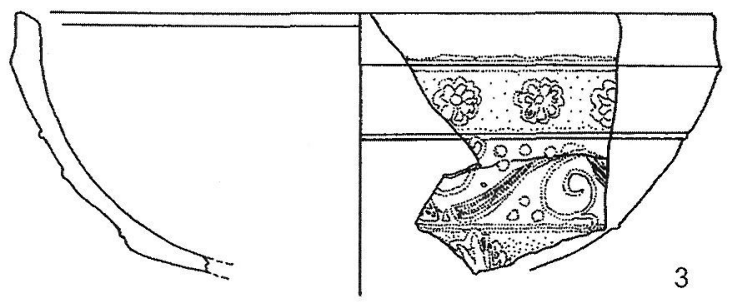

Figura 1.

deberíamos identificar como fitomorfo, aunque la rotura de la pieza nos impide apreciarlo con claridad. Posiblemente se trate de una hoja similar a las de acanto en su variedad mollis. Esta combinación existe en el repertorio decorativo de Menemakhos, compuesta por guirnaldas y rosetas de siete pétalos (Laumonier, 1977, PI. 2, 428-477, 9303), mostrando bajo estos motivos una sucesión de hojas dispuestas de forma radial, en ocasiones de acanto, como parece intuirse en este fragmento; el mismo esquema aparece también en el taller de Apollónios (Laumonier, 1977, PI. 50, 479; PI 51, 1846) y en el del monograma (Laumonier, 1977, Pl. 35, 416), aunque debido al aspecto de las rosetas y al de las hojas de acanto, con el extremo recto en lugar de replegado como suelen mostrarse en el taller de Menémakhos, tal vez pertenezca al taller de Apollónios o al del monograma, opción por la que nos decantamos. $14 \mathrm{~cm}$ de diámetro.

BARNIZ: en el lado interno presenta un barniz negro con brillo metálico, mientras que al exterior sólo se observa esta característica en la zona más próxima al borde, siendo el resto del barniz de un color negro menos intenso y mate, con zonas donde la pérdida del barniz permite apreciar la pasta. PASTA: depurada, con fracturas rectas y de color castaño claro. Se aprecia la presencia de pequeños desgrasantes de color negro, muy finos, así como una serie de puntos blancos. BIBLIOGRAFÍA: Inédito.

No INV: LA-943

FORMA: fragmento de borde.

DESCRIPCIÓN: cuatro fragmentos que forman parte de la misma pieza, no reconstruible (Fig. 1, 4). Nos encontramos ante un cuenco de borde ligeramente entrante, que presenta una banda de puntos en la zona próxima al borde, a la que sucede otra franja decorada con una sucesión de rosetas de siete pétalos entre unos motivos alargados, de tipo fusiforme,

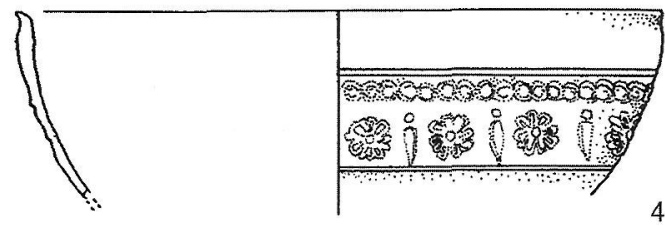

4

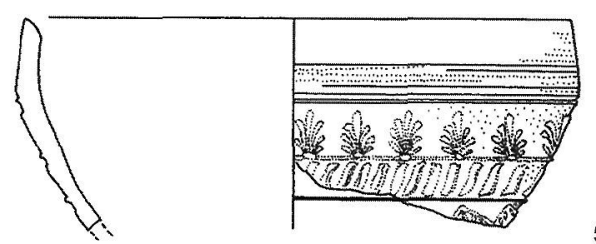

5

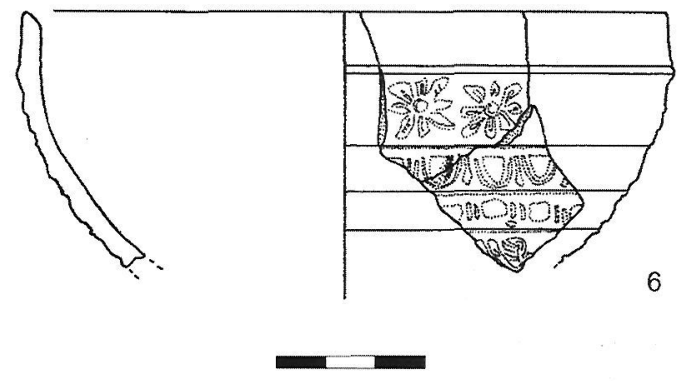

rematados en su parte superior con un punto. Estos motivos los encontramos fundamentalmente en el taller del "Cómico con bastón" (motivos fusiformes con punto encima, por ejemplo: Laumonier, 1977, PI. 26, 1112, 2096, 3104, 3199, $3443,8754-8755$ ) y en el taller del monograma, aunque es en este último donde hallamos las mayores similitudes (rosetas y bastoncillos: Laumonier, 1977, PI. 38, 878, 4352, $5630,5631-4353,5717,5635$, Téos). $13 \mathrm{~cm}$ de diámetro.

BARNIZ: tanto la parte interna como la externa presentan un barniz negro dotado de brillo metálico, que en algunos puntos, debido a las roturas, permite observar la pasta.

PASTA: depurada y de color gris.

BIBLIOGRAFÍA: Ramos Folqués y Ramos Fernández, 1976, 35-36, lám. LII, A y fig. 34, a.

\section{NoINV: LA-944}

FORMA: fragmento de borde.

DESCRIPCIÓN: fragmento de borde ligeramente entrante, perteneciente a un cuenco no reconstruible (Fig. 1, 5). La pieza presenta la franja lisa característica junto al borde, y bajo ella observamos la presencia de un friso decorado con una serie de palmetas de siete hojas, bastante esquemáticas. A continuación se ha dispuesto una serie de líneas oblicuas en relieve, que producen un efecto similar al de una soga o cordón, motivo denominado línea truncada o torsade. En la franja inmediata encontramos un motivo bastante arrasado, posiblemente una serie de hojas imbricadas, que tal vez recubría el cuenco desde esa línea hasta la base. Aunque no hemos encontrado un cuenco que repita la decoración exactamente, la aparición de este tipo de motivos caracteriza al taller del "Cómico con bastón" (Laumonier, 1977, PI.27, 4404774; entre delfines o pájaros (PI. 29, 3192); entre rosetas: PI. 29, 2110), donde las palmetas aparecen rodeadas por otros elementos como delfines, pájaros o rosetas, o bien entre 
elementos diversos (dentro del grupo "decoración vegetal" véase la pieza $n^{\circ}$ 409-1397: Laumonier, 1977, 429, PI.100, 409-1397), pero debido a la similitud de la pieza de La Alcudia con aquellas referidas en primer lugar y a que la línea truncada es exclusiva de este taller (Laumonier, 1977, PI. 26, 462; PI. 27, 4404-774), consideramos que debe formar parte del repertorio creado en el taller del "Cómico con bastón". $11 \mathrm{~cm}$ de diámetro.

BARNIZ: en el interior encontramos un barniz con una coloración rojiza, apreciando la presencia de cambios de tonalidad hacia el castaño oscuro, que podrían interpretarse como evidencias de "golpes de llama" fruto de su exposición al fuego durante la cocción. Al exterior presenta un barniz de color rojo brillante.

PASTA: arcilla de color anaranjado, con presencia de algunas vacuolas o burbujas.

BIBLIOGRAFÍA: Inédita.

\section{No INV: LA-945}

FORMA: fragmento de borde y pared.

DESCRIPCIÓN: dos fragmentos que pertenecen a la misma pieza, un cuenco de borde ligeramente entrante, no reconstruible (Fig. 1,6). Bajo una franja lisa junto al borde observamos una sucesión de rosetas de ochos pétalos, con el botón central bastante marcado. A continuación se establece otra banda decorada con una sucesión de ovas y dardos, desarrollando bajo ésta una sucesión de perlas alargadas y carretes. El fragmento está decorado además con un elemento que no hemos logrado identificar, debido a que la rotura nos permite observarlo de forma parcial, aunque posiblemente sean motivos vegetales. No hemos encontrado una sucesión similar en el repertorio ofrecido por los distintos talleres, aunque la forma de las rosetas, dotadas de unos pétalos redondeados con un surco en el centro de cada punta, y el aspecto de los otros motivos (ovas de aspecto redondeado, con el dardo a la derecha y sucesión de astrágalos; posible hoja de acanto con el borde replegado) parecen permitir su adscripción al taller del monograma. 13 $\mathrm{cm}$ de diámetro. Presenta unas anotaciones en lápiz en la superficie interna de la pieza: " $E$ " / 1957, que tal vez deban interpretarse como una indicación del año de la campaña en que se produjo su hallazgo y la letra $E$ como el nivel arqueológico al que pertenecía.

BARNIZ: tanto en su parte interna como externa la pieza presenta un barniz que oscila entre el color rojo y el naranja pálido, bastante mate.

PASTA: arcilla anaranjada con abundante desgrasante micáceo, de pequeño tamaño.

BIBLIOGRAFIA: Inédita.

\section{No INV: LA-946}

FORMA: fragmento de base.

DESCRIPCIÓN: fragmento de base de un cuenco, no reconstruible (Fig. 2, 1). Apreciamos la presencia de una serie de motivos vegetales dispuestos de forma radial, y un motivo dispuesto de forma oblicua al conjunto, posiblemente identificable con una palma. La decoración de la zona interna de la base se ha realizado con bastante resalte, superando un pequeño pie anular, muy delgado, que delimita un campo de forma circular. En este campo se ha dispuesto una serie de elementos que podriamos identificar con varios pétalos pertenecientes a una roseta. El diámetro de este campo en la base es de $6 \mathrm{~cm}$. El aspecto de la pieza nos induce a considerarla como fruto de los modelos utilizados en el taller de Philon, debido fundamentalmente a que en este taller la parte externa de la base suele decorarse empleando rosetas de ocho pétalos con estrechas similitudes en aspecto y forma. En el interior de las mismas se dispone una roseta más pequeña (Laumonier, 1977, PI. 62, 670), de la que no tenemos evidencias, pero es bastante frecuente que se repitan alrededor de estos motivos las secuencias de hojas que hemos señalado (Laumonier, 1977, PI. 63, 8675).

BARNIZ: la pieza presenta un barniz de color rojizo, mate, tanto en la zona interna como en la externa

PASTA: color anaranjado, con desgrasante micáceo muy fino. BIBLIOGRAFIA: Ramos Folqués, 1953, 107-133, lámina LXV.

\section{$N^{\circ}$ INV: LA-947}

FORMA: fragmento de cuenco.

DESCRIPCIÓN: un fragmento de pared de un cuenco no reconstruible (Fig. 2, 2). Está decorado con una serie de capullos vegetales o corazones entre los que se dispone un motivo alargado, tal vez un dardo, siempre ubicado a la izquierda del motivo. Esta primera franja decorada está delimitada en su parte inferior por un estrecho filete, bajo el cual se desarrolla una sucesión de rosetas de ocho pétalos con el botón central en bastante resalte, también enmarcada por filetes. La siguiente banda decorada presenta un contario de perlas alargadas y cuentas dispuestas en vertical, apreciando un fino trazo que las une. Tras un estrecho filete que la delimita en su parte inferior encontramos una franja sin decoración, aunque debido a su rotura posiblemente corresponde a una zona de transición hacia otro tipo de motivo próximo a la base del cuenco. Las similitudes de estos elementos de forma individualizada (Laumonier, 1977; para las rosetas: PI. 35, 403, 5881, 468; para los corazones: PI.35, 3050, 424, 403; para los astrágalos: PI. 30, 917; PI. 31, 664910, 1015; PI.34, 936-977) responden claramente a los modelos empleados en el taller del monograma, y hemos encontrado un cuenco que responde de forma idéntica a la secuencia decorativa empleada aquí en este mismo taller (Laumonier, 1977, PI. 34, 372).

BARNIZ: la pieza presenta en el lado interno un barniz de color rojizo claro, mate. En su parte externa apreciamos una coloración variable desde el negro mate hasta un color rojizoanaranjado en la zona de las perlas alargadas, con una zona de transición de color castaño.

PASTA: color rosado-anaranjado, con desgrasante micáceo muy fino.

BIBLIOGRAFÍA: Inédito.

\section{$N^{\circ}$ INV: LA-948}

FORMA: fragmento de base.

DESCRIPCIÓN: fragmento de base de un cuenco, no reconstruible (Fig. 2,3). Es una base plana de $6 \mathrm{~cm}$ de diámetro, con un pie apenas esbozado y sin decoración en esta zona. La decoración que puede apreciarse en la pieza está compuesta por una serie de motivos fitomorfos, entre los que destacan una palmeta muy esquemática, de cinco hojas, y parte de una hoja alargada dispuesta de forma radial que podríamos identificar como "hojas acuáticas". En la superficie de la base se ha realizado un grafito en caracteres griegos $\varphi \imath \lambda_{\imath}[$ [, genitivo empleado de forma usual para indicar origen o propiedad ${ }^{3}$, que debemos interpretar como la marca

\footnotetext{
${ }^{8}$ Philon junto a Menémakhos es el taller que ha proporcionado mayor número de firmas (sirvan de ejemplo: Laumonier, 1977, PI. 57, 5005-5002, 5007; PI.61, 1967) probablemente porque ambos realizaron gran número de pequeños cuencos de fondo plano sin roseta. Se observa un predominio de los cuencos decorados con godrones (11 ejemplares firmados) y con decoración de escamas (19 ejemplares). Este hecho ha suscitado una controversia relativa a la difusión de sus motivos, barajándose la posibilidad de que existan imitadores o bien que se deba a la presencia de varios artistas en e mismo taller (Laumonier, 1977, 247).
} 

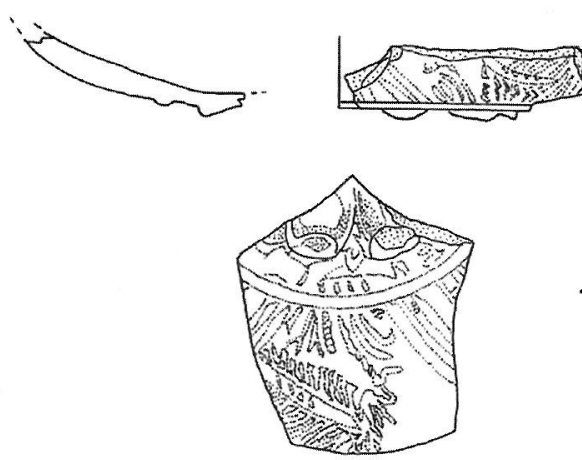

1

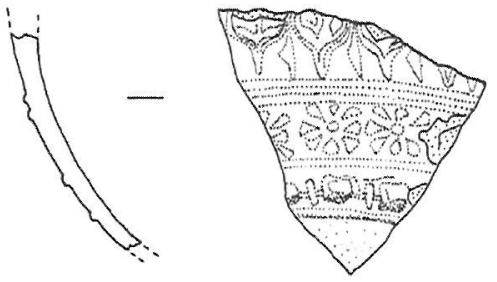

2
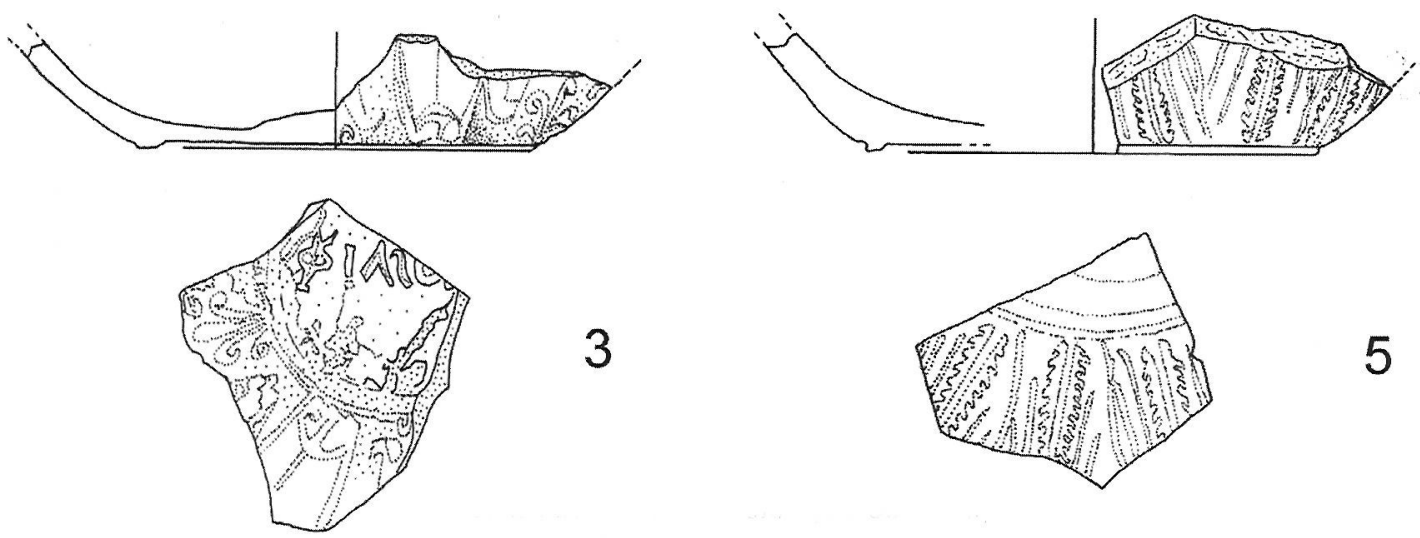

3

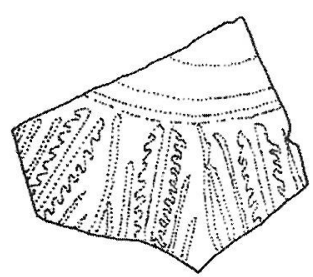

5
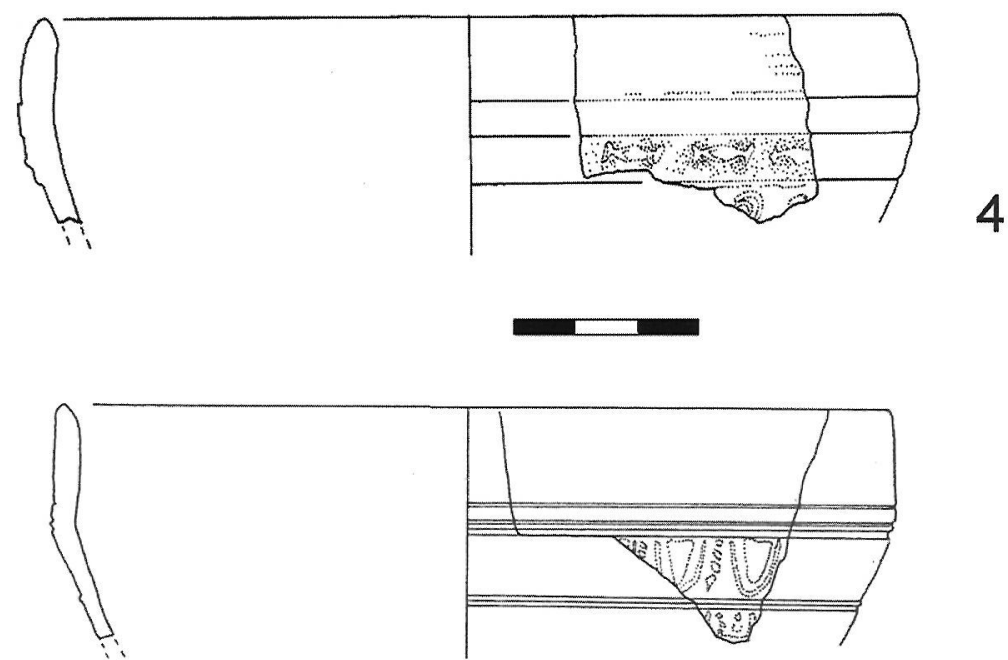

6

Figura 2.

del alfarero o taller donde se realizó la pieza. Sobre la arcilla se trazó la firma, que se realiza de forma preferente mediante incisiones tras el modelado (Laumonier, 1977, 13).
BARNIZ: la pieza presenta un barniz de color rojizo tanto al interior como al exterior, donde se encuentra ligeramente erosionado y permite observar la pasta. 
PASTA: de color rosado-anaranjado, con desgrasante micáceo muy fino.

BIBLIOGRAFÍA: Inédito.

No INV: LA-949

FORMA: fragmento de borde.

DESCRIPCIÓN: fragmento de borde ligeramente entrante, perteneciente a un cuenco no reconstruible (Fig. 2, 4). Está decorado con un contario de "lazos" o astrágalos, y bajo ella se esbozan una serie de motivos parcialmente arrasados, que podrian identificarse con la parte superior de una S, dispuesta en vertical. La identificación de esta pieza nos remite a modelos empleados en el taller de Menémakhos, debido a la forma característica de los astrágalos (Laumonier, 1977, PI. $13,5847) .14 \mathrm{~cm}$ de diámetro.

BARNIZ: el interior presenta un barniz de color rojoanaranjado, mientras que en el exterior se muestra con una variedad de tonos entre el castaño claro, con una serie de manchas más oscuras, hasta la línea de lazos; a continuación el tono del barniz se aclara hacia un color más rojizo, estando esa zona bastante arrasada.

PASTA: anaranjada con abundante desgrasante micáceo. BIBLIOGRAFÍA: Inédito.

\section{$N^{\circ}$ INV: LA-950}

\section{FORMA: fragmento de base.}

DESCRIPCIÓN: fragmento de base de un cuenco, no reconstruible (Fig. 2, 5). La decoración de esta pieza muestra una serie de palmas o de hojas de helecho, estrechas y alargadas, inscritas en el interior de otros motivos vegetales, lo que nos hace inclinarnos a favor de su identificación como hojas de helecho. Se aprecian algunos motivos fitomorfos dificilmente identificables. La base no presenta decoración, y tiene un pie muy poco pronunciado. Estos motivos no son frecuentes entre los talleres jonios, aunque sabemos de su existencia en Cartagena (Cabrera, 1978-1979, 99, $\mathrm{n}^{\circ} 32$ ), donde se plantea la posibilidad de que se trate de imitaciones. Es posible que formen parte del repertorio decorativo del grupo "decoración vegetal" que Laumonier estableció, pues encontramos en él una serie de fragmentos donde los motivos son muy parecidos (Laumonier, 1977, PI. 100, 9760). Su diámetro es de $7 \mathrm{~cm}$.

BARNIZ: color castaño, con algunos reflejos violáceos sobre ambas superficies.

PASTA: arcilla ocre, de aspecto más basto que el resto de las piezas examinadas, sin desgrasante micáceo. BIBLIOGRAFÍA: Laumonier, 1962, 43-47, Pt. VI.

No INV: LA-951

FORMA: fragmento de borde.

DESCRIPCIÓN: fragmento de borde ligeramente entrante, de un cuenco no reconstruible (Fig. 2, 6). Bajo la franja más cercana al borde, desprovista de decoración, encontramos un friso decorado con ovas y dardos, al que sucede un motivo que sólo apreciamos de forma parcial por la rotura, pudiendo tratarse de la evidencia de una banda de capullos vegetales con dardos. Destacamos las similitudes existentes entre esta pieza y las realizadas siguiendo el mismo patrón en el taller del monograma (Laumonier, 1977, Pl. 47, 8393). $12 \mathrm{~cm}$ de diámetro.

BARNIZ: rojo oscuro a castaño en la parte interna, presentando en el borde una zona ennegrecida y con brillo metálico. En la superficie externa el barniz es de color negro, presentando brillo metálico por zonas, aunque se aprecia la pérdida de éste en otras.

PASTA: anaranjada, depurada y con desgrasante micáceo muy fino.
BIBLIOGRAFÍA: Inédito.

NoINV: LA-953

FORMA: fragmento de borde.

DESCRIPCIÓN: fragmento de borde de un cuenco, ligeramente entrante, no reconstruible (Fig. 3, 5). Tras una franja desprovista de decoración, la más cercana al borde, se dispone una serie de ondas u olas, enmarcada por dos finos filetes. Bajo esta franja encontramos un elemento que no podemos identificar con claridad debido a que la rotura de la pieza lo ha seccionado. Podria tratarse del extremo apuntado de una hoja. La utilización de una serie de ondas u olas es un motivo que aparece en distintos talleres, fundamentalmente en el de Menémakhos y del monograma (Laumonier, 1977, taller de Menémakhos: Pl. 12, 5605-5606; monograma: Pl.17, 9570; PI. 42, 74-42, 5607; otros ejemplares en PI. 32), por lo que no podemos adscribir de forma definitiva un taller concreto para esta pieza. $11 \mathrm{~cm}$ de diámetro.

BARNIZ: en la superficie interna se aprecia un oscurecimiento del borde, que presenta tonos que van desde el color castaño al negro, oscilando el resto de la pieza entre tonos castaño claro y rojizos. En la superficie externa se aprecia un barniz de color negro, con reflejo metálico, dispuesto hasta la zona donde encontramos el filete que delimita la parte inferior de la franja de olas. A partir de ese punto, el barniz adopta una tonalidad más próxima a los tonos rojizos de la superficie interna. El barniz está bastante erosionado y permite apreciar la pasta.

PASTA: su tonalidad oscila entre el color rosado y el naranja claro, observando en su composición la presencia de desgrasante micáceo muy fino.

BIBLIOGRAFÍA: Inédito.

\section{No INV: LA-954}

FORMA: fragmento de borde.

DESCRIPCIÓN: fragmento de borde ligeramente entrante, de un cuenco no reconstruible (Fig. 3,1). La decoración está bastante arrasada, apreciándose con suficiente claridad la existencia de una serie de rosetas, aunque debido a esta circunstancia no podemos determinar cuál es el número exacto de pétalos que la conforman. El botón central está bien definido. Bajo este motivo parece disponerse otra banda decorada, aunque no se aprecian con claridad los elementos que la conforman. El friso de rosetas de siete pétalos es motivo que debido a su gran difusión no permite realizar una identificación precisa del taller en que se originó. $13 \mathrm{~cm}$ de diámetro.

BARNIZ: de color rojo-anaranjado en la superficie interna, muestra unas tonalidades próximas al castaño en la externa, aclarándose de forma progresiva desde el borde hacia la base, hasta alcanzar una tonalidad rojiza mate.

PASTA: de color anaranjado claro, con desgrasante micáceo muy fino.

BIBLIOGRAFIA: Inédito.

No INV: LA-955

FORMA: fragmento de borde.

DESCRIPCIÓN: fragmento de borde ligeramente entrante, perteneciente a un cuenco no reconstruible (Fig. 3, 2). La decoración que podemos observar consiste en una franja de motivos entrelazados, un tipo bastante difundido. $12 \mathrm{~cm}$ de diámetro.

BARNIZ: en la superficie interna se presenta dispuesto en dos zonas de coloración distinta: castaño oscuro junto al borde y rojizo luego; sin embargo, en la superficie externa, el barniz de la zona cercana al borde es rojizo y en la zona 


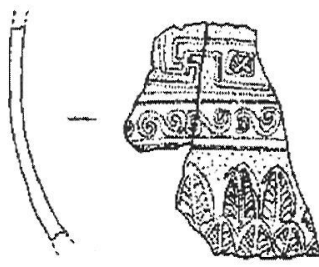

\section{1}
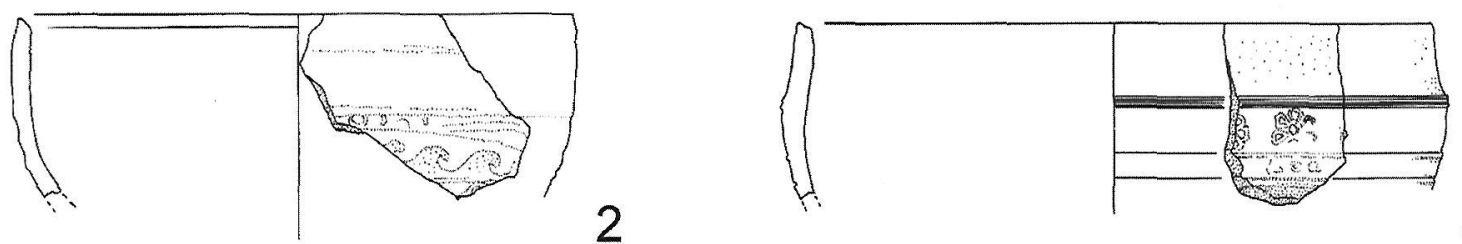

2

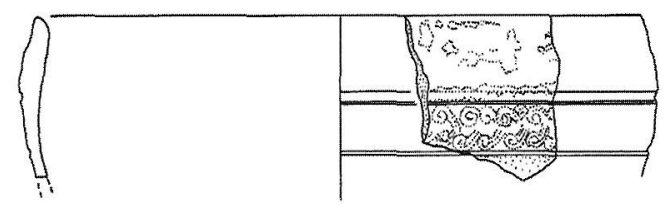

4

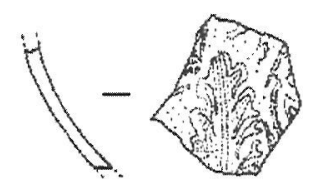

5

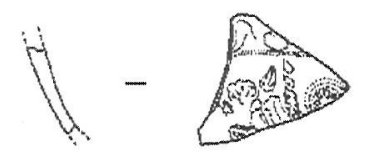

6
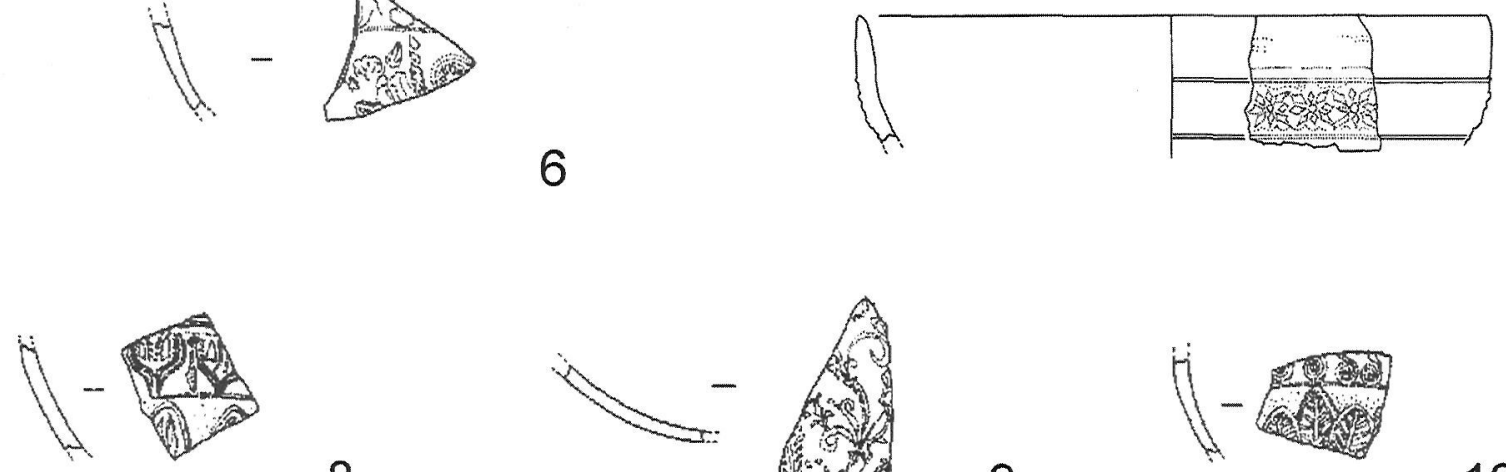

8
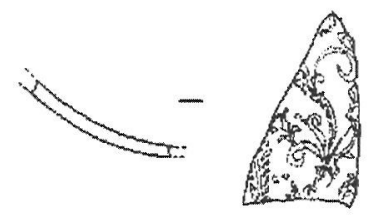

9

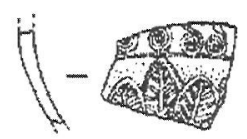

10

Figura 3

cercana a la rotura presenta un tono castaño oscuro, sin brillo. Se da la circunstancia que la pieza ha perdido gran parte del barniz externo.

PASTA: anaranjada, con desgrasante micáceo muy fino. BIBLIOGRAFÍA: Inédito.

NoINV: LA-958

FORMA: fragmento de borde.

DESCRIPCIÓN: fragmento de borde ligeramente entrante, perteneciente a un cuenco no reconstruible (Fig. 3, 3). Está decorado con una sucesión de rosetas de ocho pétalos con los extremos apuntados que adoptan una apariencia estrellada, enmarcadas entre dos finos filetes. Estos motivos son muy frecuentes, pero tal vez pertenezcan en este caso al taller del monograma (Laumonier, 1977, PI.65, 5487). 13 $\mathrm{cm}$ de diámetro.

BARNIZ: tanto en el interior como en el exterior se presenta de color negro, aunque en la parte interior es bastante mate, siendo más intenso y con brillo metálico en el exterior. Está erosionado en varios puntos de la pieza.

PASTA: de color anaranjado-beige claro, con desgrasante micáceo.

BIBLIOGRAFÍA: Inédito.

No INV: LA-952

FORMA: fragmento de cuenco. 
DESCRIPCIÓN: 2 fragmentos de pared de un cuenco, que pertenecen a la misma pieza, aunque ésta no es reconstruible (Fig. 3,6). En este ejemplar se decora la superficie mediante la sucesión de un motivo de meandros y ocupa la banda inferior una sucesión de " $S$ " acostadas que da paso a una superficie completamente decorada con hojas imbricadas, redondeadas, con nervio central y pequeñas nervaduras laterales marcadas con líneas dispuestas de forma oblicua. Aunque los dos primeros motivos enumerados son bastante frecuentes en todos los talleres, la utilización de hojas imbricadas del tipo mencionado es característica del taller del monograma. Sin embargo, cuencos pertenecientes al taller de Menémakhos repiten la decoración del borde de nuestra pieza (Laumonier, 1977, Pl. 2, 428-477), pero debido a que las hojas imbricadas deberían ser más triangulares, es muy probable que la atribución al taller del monograma sea la correcta.

BARNIZ: en la zona interna presenta un barniz de color rojo claro, bastante mate, mientras que al exterior presenta un barniz que oscila entre zonas con un tono castaño oscuro y otras de tonalidad más clara. Ligeramente erosionado, permite apreciar la pasta en varios puntos de la pieza.

PASTA: anaranjada, con desgrasante micáceo muy fino. BIBLIOGRAFIA: Ramos Folqués, 1990, 129, lámina 36.

No INV: LA-956

FORMA: fragmento de cuenco.

DESCRIPCIÓN: fragmento de pared de un cuenco, perteneciente a una pieza no reconstruible (Fig. 3, 7). La decoración está compuesta por una serie de motivos fitomorfos, no identificables la mayoria de ellos, y una hoja similar a las de acanto en su variedad mollis, aunque por las dimensiones del fragmento y el empleo frecuente de este recurso decorativo no hemos podido realizar la identificación de su taller de origen.

BARNIZ: rojizo al interior, en su superficie externa presenta un tono castaño, parcialmente erosionado sobre los motivos decorativos.

PASTA: anaranjada, con desgrasante micáceo.

BIBLIOGRAFIA: Inédito

No INV: LA-957

FORMA: fragmento de cuenco.

DESCRIPCIÓN: fragmento de pared de cuenco, no reconstruible (Fig. 3,4). Decorado con dos franjas: en la primera de ellas apreciamos una serie de motivos no muy definidos, tal vez relacionables con una franja de ovas y dardos lisos. Existe un filete que separa este motivo de la siguiente franja, decorada con una cabeza de toro y una guirnalda que realiza una curva, en el interior de la cual se dispone un motivo identificable con una roseta inserta en un circulo. Este tipo de motivos se realizan en el taller del "cómico con bastón", en el del monograma y en el de Heraios (Laumonier, 1977, cómico con bastón: PI. 26, 1111; monograma: PI. 39,8747 ; Heraios: PI. 129, 3481), aunque podria tratarse de un producto del último taller mencionado si la banda superior estuviese decorada con ovas y dardos, que en la pieza parecen intuirse, aunque no podemos asegurar esta identificación por lo arrasado que aparece el motivo.

BARNIZ: rojizo en la superficie interna. En el exterior se presenta en dos tonalidades: negro mate hasta el filete, desde donde lo encontramos de color rojizo.

PASTA: de color rosado-anaranjado. No se aprecian desgrasantes, muy depurada.

BIBLIOGRAFÍA: Inédito.

No INV: LA-959

FORMA: fragmento de cuenco
DESCRIPCIÓN: fragmento de pared de un cuenco no reconstruible (Fig. 3,8). Su decoración la componen una sucesión de corazones o capullos vegetales bajo la que se desarrollan hojas imbricadas. La forma redondeada de las hojas (Laumonier, 1977, PI. 42, 13; PI. 41, 8717, 114) y el aspecto estriado que ofrecen las líneas internas de los corazones nos remiten a modelos creados en el taller del monograma (Laumonier, 1977, PI. 30, 1009; PI. 34, 372).

BARNIZ: tanto en la superficie interna como en la externa presentan un barniz de color castaño oscuro, brillante. PASTA: de color anaranjado, depurada.

BIBLIOGRAFIA: Ramos Folqués, 1990, 129, lámina 36.

$N^{\circ}$ INV: LA-960

FORMA: fragmento de cuenco.

DESCRIPCIÓN: fragmento de pared, de un cuenco no reconstruible (Fig. 3, 9). Decoración formada por una sucesión de motivos estilizados vegetales, formando roleos rematados en finas volutas. Debido al reducido tamaño del fragmento es muy difícil realizar su atribución a un taller determinado.

BARNIZ: en la zona interna es de color castaño oscuro, siendo del mismo tono en la externa. No tiene brillo.

PASTA: depurada, de color rosado-anaranjado.

BIBLIOGRAFÍA: Inédito.

\section{$N^{\circ}$ INV: LA-961}

FORMA: fragmento de cuenco.

DESCRIPCIÓN: fragmento de pared de un cuenco no reconstruible (Fig. 3, 10). Se dispone la decoración en dos zonas, separadas por un filete: en la primera de ellas encontramos una banda de " $S$ " dispuestas en vertical hacia la derecha, y bajo el filete encontramos una sucesión de hojas imbricadas, que marcan en su interior las nervaduras mediante una serie de trazos oblicuos al eje central. Las características de esta decoración nos remiten al taller del monograma (Laumonier, 1977, PI., 41, 189; PI. 42,240, 8528). BARNIZ: rojizo en interior y exterior, pero presentando en la zona decorada con "S" un barniz de color negro y con brillo metálico.

PASTA: de color rosado-anaranjado, con desgrasante micáceo muy fino

BIBLIOGRAFÍA: Ramos Folqués, 1990, 129, lámina 36

\section{N ${ }^{\circ}$ INV: LA-1018}

FORMA: cuenco.

DESCRIPCIÓN: cuenco reconstruido a partir de seis fragmentos: dos fragmentos de borde ligeramente entrante, un fragmento de pared y tres fragmentos de base (Fig. 4, 1). La reconstrucción de la pieza no ofrece el perfil auténtico, pues no contamos con datos relevantes como la altura total. La decoración del vaso se distribuye en una franja de finos motivos fitomorfos con delicadas volutas como remate de los apéndices vegetales. Bajo este motivo se dispone una decoración formada por la sucesión de series de hojas imbricadas, apuntadas y con las nervaduras del interior marcadas mediante líneas oblicuas. La base presenta un pie poco marcado, de $5 \mathrm{~cm}$ de diámetro. El diámetro del borde de este cuenco es de $13^{\prime} 5 \mathrm{~cm}$. Para la franja del borde tenemos una serie de paralelos claros en el taller de Menémakhos (Laumonier, 1977, Pl. 12, 4217-4227, 8739; Pl. 13, 1800), en el taller "de las estrellas de seis brazos ahuecados" (donde sin embargo, las hojas imbricadas muestran tan sólo la nervadura central marcada: Laumonier, $1977,24-25$, PI. 87, 129) o en el taller "de la pequeña rosa en espiral" (Laumonier, 1977, PI. 48, 239). Este último es el que mayor similitud muestra con el fragmento que presentamos, aunque debido a la difusión de las hojas 


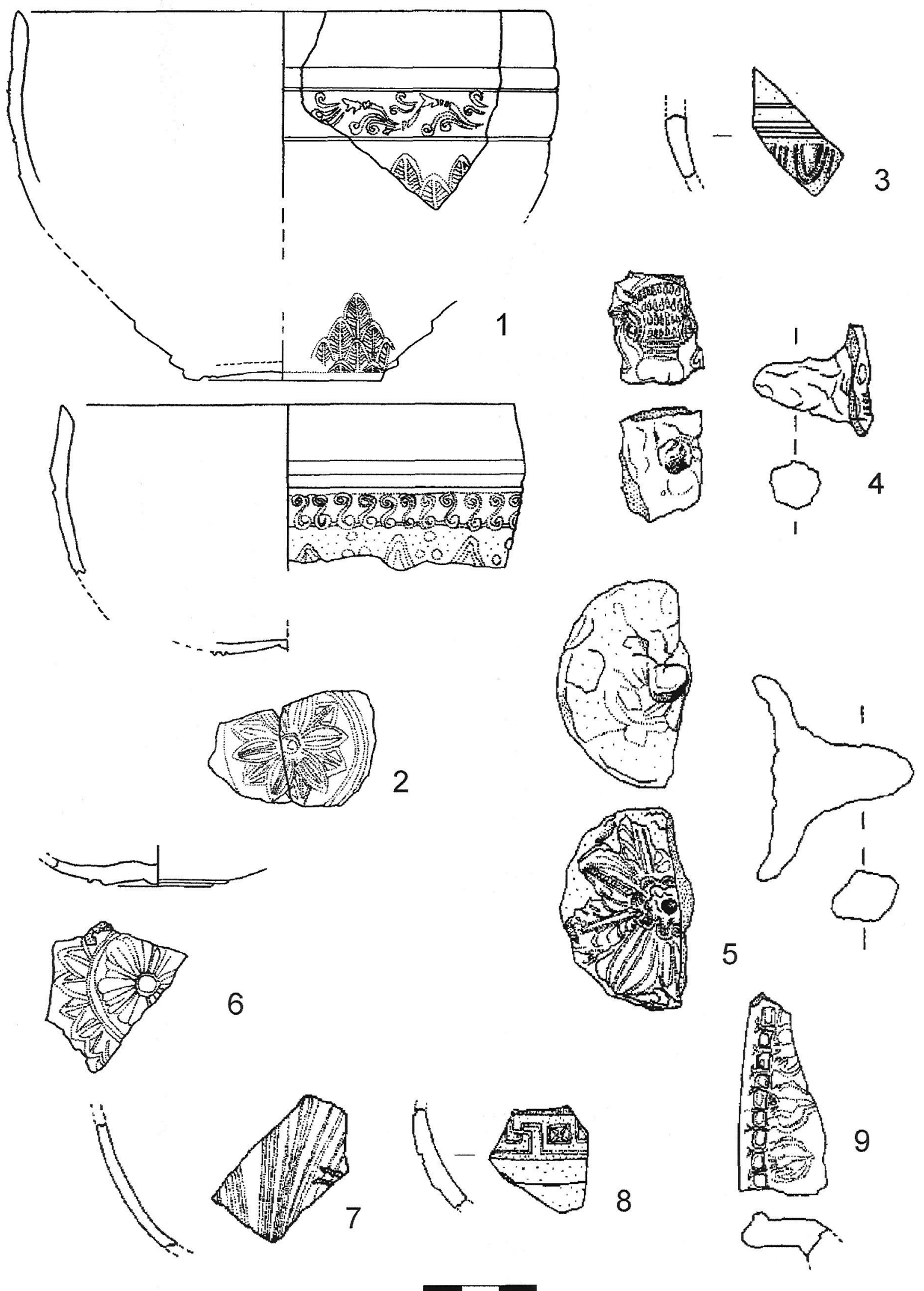

Figura 4. 
imbricadas, muy similares en el taller del monograma, no podemos asegurar a cuál de todos éstos pertenece.

BARNIZ: al interior presenta un color castaño oscuro en la zona cercana al borde, aclarándose en la zona del fondo. La superficie exterior presenta un barniz de color negro, mate, aunque con brillo metálico en ciertas zonas, que deja paso según la zona más o menos próxima al borde a tonos cercanos al castaño claro, mientras que en la base se observa un color rojizo.

PASTA: Por la reconstrucción que se realizó de la pieza no hemos podido observar más que el color, anaranjado, a través de las zonas donde el barniz se ha erosionado. No podemos concretar si existen o no desgrasantes.

BIBLIOGRAFÍA: Inédito.

\section{$N^{\circ}$ INV: LA-1020}

FORMA: cuenco

DESCRIPCIÓN: cuenco reconstruido a partir de cinco fragmentos: tres fragmentos de borde ligeramente entrante $y$ dos fragmentos de base (Fig. 4, 2). Como en el caso anterior, no contamos con el perfil completo de la pieza. La decoración se compone a partir de una banda de "S" dispuestas en vertical hacia la izquierda, bajo la cual se disponen una serie de motivos que podríamos identificar con fitomorfos, más concretamente con hojas apuntadas en las que se ha marcado doblemente el contorno, dispuestas de modo radial sobre la superficie del cuenco. Entre ellas encontramos agrupaciones de puntos, en número de tres cada vez, realizando formas tendentes al triángulo. La superficie externa de la base se encuentra decorada con una roseta de doce pétalos $(6+6)$ inserta en dos círculos concéntricos. La decoración del borde muestra motivos (banda de " $S$ " verticales, agrupaciones de puntos y hojas de tendencia lanceolada) muy similares a los que encontramos en el taller de Menémakhos (Laumonier, 1977, PI. 10, 8635 y Téos), aunque la decoración de la base ofrece mayores dificultades de interpretación, pues el motivo representado, una roseta de $6+6$ pétalos, muestra sus mejores paralelos en las producciones del taller del monograma (Laumonier, 1977, PI. 30, 1975, 1976). Las noticias que tenemos del hallazgo (Ramos Folqués, 1966) presentan el vaso sin restaurar hasta 1975 (Ramos Fernández, 1975), momento en que posiblemente se unieron piezas procedentes de la misma excavación creyéndolas pertenecientes al mismo vaso. El diámetro de esta pieza es de 12 $\mathrm{cm}$ en el borde y $4 \mathrm{~cm}$ en la base.

BARNIZ: tanto en su parte interna como en la externa se observa un barniz de color rojo, mate, con algunas manchas más oscuras o castañas en la superficie externa, resultado posible de su exposición al fuego.

PASTA: la reconstrucción de la pieza no nos ha permitido observar una sección de la misma, aunque a través de pequeñas erosiones del barniz se aprecia una tonalidad anaranjada y se constata la presencia de desgrasantes micáceos.

BIBLIOGRAFíA: Ramos Folqués, 1966, 71-76, lám. XV, fig. 2; Ramos Fernández,1975, 146, lám. LXXI, fig. 2,3; Ramos Folqués, 1990, 129, lám. 36.

\section{NoINV: LA-1700}

FORMA: fragmento de cuenco.

DESCRIPCIÓN: fragmento de pared, muy próximo al borde del cuenco, que presenta una decoración formada por una franja de ovas y dardos delimitada en su parte superior por un estrecho filete, disponiéndose los dardos a la derecha de cada ova (Fig. 4, 3). Este motivo es muy frecuente, pero debido a las similitudes qe presenta con otras piezas, creemos que puede pertenecer al taller del monograma.
BARNIZ: bastante erosionado, muestra un color negro mate en la superficie interior, mientras que en la parte externa del cuenco se observa una gradación desde el negro con reflejo metálico hasta el color castaño.

PASTA: anaranjada con desgrasante micáceo muy pequeño. BIBLIOGRAFIA: Inédito.

NoINV: LA-1813

FORMA: fragmento de punzón.

DESCRIPCIÓN: fragmento de punzón o estampilla realizado en terracota, dotado de una superficie con la que mediante la presión ejercida sobre su mango se pueda obtener un motivo en negativo (Fig. 4, 4). La decoración resultante sería un bucráneo o una cabeza de toro en posición frontal, sobre la que se han marcado detalles alusivos al pelaje y a características del morro. La cabeza de bóvido está rodeada por una cinta o banda que realiza una curva que posiblemente enmarque todo el motivo, sin encerrarlo completamente, pues queda a la altura del morro girada hacia el exterior formando una ligera voluta.

BARNIZ: no dispone de barniz.

PASTA: de color beige claro a rosado, con desgrasantes formados por una serie de puntos blancos visibles también en la superficie de la pieza.

BIBLIOGRAFIA: Ramos Fernández, 1995, 88, fig. 587; ídem, 165, foto 19.

\section{$N^{\circ}$ INV: LA-1815}

FORMA: fragmento de punzón.

DESCRIPCIÓN: fragmento de punzón o estampilla, en cuya superficie trabajada se aprecia un motivo en negativo, por lo que su empleo debió proporcionar superficies en resalte (Fig. $4,5)$. La decoración que presenta refleja una roseta central, con botón circular en resalte, dotada de varios pétalos dobles, aunque no podemos precisar su número total debido a la fragmentación de la pieza. Alrededor de ésta se disponen de forma radial una serie de fitomorfos, que identificamos con dos tipos de hojas: un tipo lo constituyen una serie de hojas lanceoladas en las que se representa con un trazo en resalte la superficie y la nervadura central, mientras que el otro lo representan hojas similares a las de acanto. La disposición de las mismas nos hace pensar que el punzón tuvo en origen cuatro hojas de cada tipo.

BARNIZ: la pieza no presenta ningún tipo de barniz.

PASTA: de color beige claro-rosado, en la fractura se aprecia un núcleo de color gris pálido. La pasta presenta desgrasantes pequeños de color blanco.

BIBLIOGRAFÍA: Ramos Fernández, 1995, 88, fig. 586.

$N^{\circ} \cdot$ INV: LA-2470

FORMA: fragmento de base.

DESCRIPCIÓN: fragmento de base de un cuenco, no reconstruible (Fig. 4, 6). La decoración de la pieza presenta un círculo en el centro de la zona exterior de la base, en el que se inserta una roseta con el botón central marcado. Los pétalos presentan un extremo redondeado, observando que existen unos de mayor tamaño entre pétalos más estrechos que los flanquean. No conocemos el número total de pétalos debido a la rotura que presenta la pieza, posiblemente seis de los grandes rodeados cada uno por otros dos pétalos más estrechos. Unidos al filete que delimita este campo, encontramos una serie de hojas imbricadas, aunque en este caso se marca únicamente la nervadura central. El aspecto de la roseta de pétalos grandes y redondeados, rodeada por hojas imbricadas de forma redondeada, tal vez deba atribuirse al taller del monograma (Laumonier, 1977, PI. 41, 120, $122-$ 329). El diámetro de la base es de $3^{\prime} 8 \mathrm{~cm}$. 


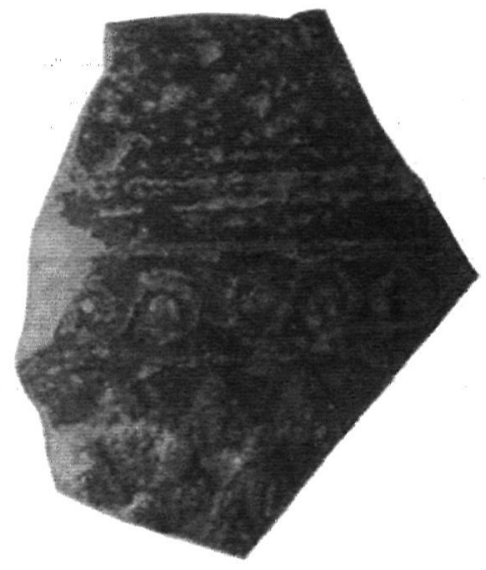

Figura 5.

BARNIZ: de color rojo mate tanto en la superficie interna como en la externa.

PASTA: anaranjada con desgrasante micáceo.

BIBLIOGRAFÍA: Ramos Folqués, 1962, 5, lám. III, 3; Ramos Folqués, 1990,129,lám.36.

No INV: LA-3685

FORMA: fragmento de cuenco.

DESCRIPCIÓN: fragmento de pared de un cuenco, no reconstruible (Fig. 4,7). Decorado con líneas ascendentes desde la base, con ligero relieve y tendencia redondeada hacia los extremos. Tal vez se trate de una decoración de "godrones" con el limbo central en relieve. Estos motivos gozan de bastante popularidad y son varios los talleres que los realizan, siendo muy difícil su atribución sin tener evidencias de la zona del borde superior.

BARNIZ: varía entre tonos oscuros y claros de castaño, con brillo metálico en algunas zonas y reflejos violáceos.

PASTA: de color rosado-anaranjado, no muy depurada y sin desgrasantes micáceos.

BIBLIOGRAFIA: Ramos Fernández, 1995, 91, fig. 618.

No INV: LA'99 / TO-1039-19

FORMA: fragmento de cuenco.

DESCRIPCIÓN: fragmento de pared de un cuenco no reconstruible, donde la pieza muestra una franja en la que se inserta un meandro regular con un pequeño cuadrado, decorado mediante cuatro pequeños radios en cruz alrededor de un punto central, lo que nos induce a pensar que podria tratarse de una roseta de cuatro pétalos muy esquematizada (Fig. 4, 8). Este motivo es bastante frecuente en el repertorio decorativo empleado por varios talleres, como son el de Menémakhos (Laumonier, 1977, PI. 2, 428-477, 1957; PI. 4, 1958; PI. 9, 8632; PI. 10, 5020,5085) o el del monograma (Laumonier, 1977, PI. 30, 9019, 1185; PI. 31, 453; PI. 32, 1420; PI. 33, 397; PI. 36, 1282), por lo que resulta muy complicado atribuirlo a un taller concreto.

BARNIZ: rojizo, con una mancha de color castaño posiblemente fruto de un golpe de llama durante la cocción.

PASTA: anaranjada, con desgrasantes micáceos muy finos. BIBLIOGRAFÍA: perteneciente a los materiales arqueológicos recuperados en la excavación de las Termas occidentales, permanece todavía inédito. Se da la circunstancia de que es el único fragmento al que podemos adscribir un contexto arqueológico perfectamente establecido ${ }^{9}$

$N^{\circ}$ INV: pieza $\sin n^{\circ}(1)$

FORMA: fragmento de cuenco.

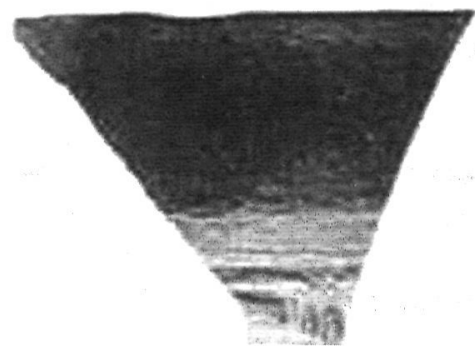

Figura 6.

DESCRIPCIÓN: fragmento de borde de un cuenco, no reconstruible (Fig. 5). La decoración la componen una banda de "S" tumbadas, enmarcada por dos filetes. Bajo esta franja se dispone una sucesión de hojitas imbricadas, esquematizadas y similares a rombos, con la nervadura central marcada. Debido a este aspecto triangular de las hojas podría clasificarse como perteneciente al taller de Menémakhos, unido al hecho de que las bandas de " $S$ " son bastante frecuentes en sus producciones.

BARNIZ: parcialmente erosionado.

PASTA: no se ha podido observar.

BIBLIOGRAFÍA: En el proceso de catalogación e inventario general de los fondos no se ha encontrado esta pieza, por lo que no se pueden indicar las características del barniz ni de la pasta. Sin embargo, conocemos su existencia por la publicación de una foto de la pieza en Ramos Folqués, 1990, 129, lám. 36.

$N^{\circ}$ INV: pieza $\sin n^{\circ}(2)$

FORMA: fragmento de borde

DESCRIPCIÓN: un fragmento de borde, perteneciente a un cuenco no reconstruible (Fig. 6). Presenta una zona decorada con unos motivos semejantes a meandros y cuadrados con roseta esquemática en su interior, semejante a la pieza LA952, aunque la rotura de la pieza dificulta mayores precisiones. Es un motivo bastante difundido, por lo que resulta muy difícil su atribución.

BARNIZ: brillante.

PASTA: no se ha podido apreciar.

BIBLIOGRAFİA: No se ha encontrado este fragmento durante el proceso de inventario general, aunque conocemos su existencia por su presencia por fotografías (Ramos Folqués, 1990, 129, lám. 36).

\section{ESTUDIO}

\subsection{Formas, pastas y barnices}

Como ya señaló G. Siebert (Siebert, $1980,58-61)$, los estudios sobre este tipo de

\footnotetext{
9 Fragmento hallado en la Unidad Estratigráfica UE 1039 en el sondeo "superior lienzo centro" (SLC). Esta unidad estratigráfica la constituye un estrato arcilloso, castaño, con abundantes restos de cal disgregada, que dan una tonalidad blanquecina al paquete. Bajo UE 1000 y cubriendo al muro norte de la natatio así como a parte del relleno de la misma, UE 1081. Agradecemos a M. Tendero esta información.
} 


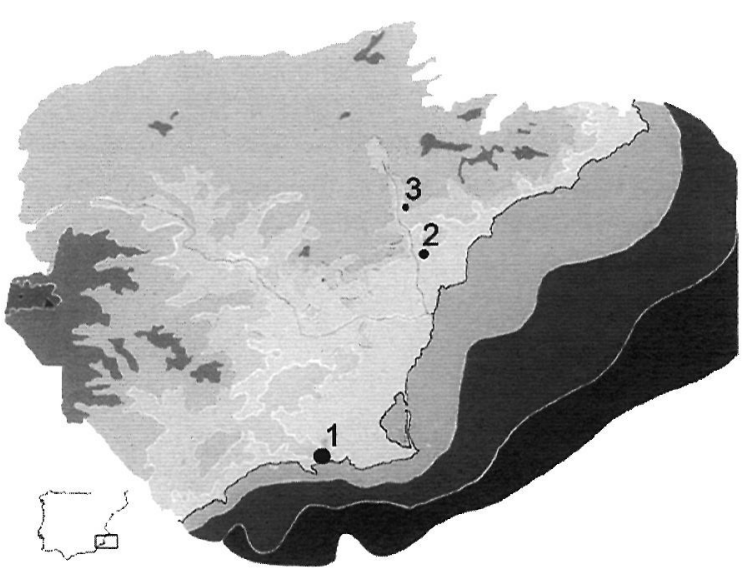

Figura 7: Plano de ubicación de yacimientos con cuencos de relieves en el entorno de La Alcudia: 1. Carthago Nova (Cartagena, Murcia); 2. La Alcudia (Elche, Alicante); 3. El Monastil (Elda, Alicante).

cerámicas pueden abordarse desde diferentes vías de profundización ${ }^{10}$. Sin embargo, el criterio formal, que en otras producciones cerámicas se convierte en un parámetro fundamental para la clasificación, se ha devaluado por los escasos resultados que ofrece en conjuntos de pequeño volumen como el que estudiamos. A pesar de que se ha demostrado mediante el estudio comparativo que los cuencos revelan variaciones del perfil correspondientes a modas regionales, existen grandes reticencias y reservas a la hora de considerar esta característica como un valor inalterable ${ }^{11}$. El panorama se complica aún más cuando observamos que los grupos establecidos por Courby ${ }^{12}$ no reflejan una realidad firmemente establecida, ya que no se pueden diferenciar las formas locales debido al desconocimiento de las mismas, incrementando la dificultad de estudio el hecho que los artesanos copian voluntariamente las decoraciones de modelos lejanos sin imitar jamás la forma (Siebert, 1980, 59).

Como hemos podido apreciar, el repertorio formal de las cerámicas de relieves de La Alcudia es bastante homogéneo, pues con mayor o menor grado de curvatura, todos los fragmentos de borde estudiados presentan un perfil entrante. Las formas que presentan este tipo de bordes han sido identificadas como producciones de talleres jonios, cuyo mejor testimonio lo constituye el estudio realizado por Laumonier (Laumonier, 1977) de los miles de fragmentos hallados en las excavaciones de Delos.

Este dato es bastante significativo debido a que los cuencos hallados en los yacimientos situados en el territorio circundante ${ }^{13}$ presentan unos perfiles similares a los existentes en La Alcudia (Fig. 7). Tal es así, que todos los fragmentos de borde hallados en El Monastil muestran un borde entrante o recto ligeramente entrante ${ }^{14}$, mientras que sólo conocemos la existencia de un fragmento de borde exvasado en el conjunto de cerámicas helenísticas de relieves procedente de Cartagena ${ }^{15}$, donde vuelve a ser mayoritaria la presencia de cuencos de borde entrante ${ }^{16}$.

Las dimensiones de los cuencos de La Alcudia nos ponen en relación con piezas cuyos diámetros en la parte del borde oscila entre los 11 y los $14 \mathrm{~cm}$ de diámetro, mientras que los

\footnotetext{
${ }^{10}$ Siebert se referia a los estudios "tradicionales" o basados en aproximaciones iconográficas, a los estudios fundamentados en aspectos formales o a las iniciativas destinadas a individualizar grupos de vasos para atribuirlos a una serie de especialistas o "artesanos", de los que siempre quedaban evidencias de gusto decorativo o "estilo" (Siebert, 1980, 58-61).

${ }^{11}$ F. Courby (1922) distinguió entre los vasos "delios" - en realidad jonios - con el borde vuelto hacia el interior o entrante, y los vasos de la propia Grecia, con borde exvasado. "Me parece imposible atribuir a toda esta evolución, una significación cronológica, y más conociendo las variantes considerables dentro del perfil de los cuencos firmados por el mismo fabricante" (Siebert, 1978, 95-96).
}

${ }^{12}$ Courby establece variedades regionales en función de los perfiles y la forma del labio. Es por ello que diferencia varios grupos: Beocia: donde el borde presenta un labio colgante o desplomado con un repliegue más o menos anguloso; Chipre: con el fondo más plano y el reborde en "dobladillo"; Peloponeso: oposición entre un tipo argivo-corintio (línea de pared tensa) y otro del Noroeste de la Península, representado por los vasos de Elide y de Acaya (panza redondeada coronada por un reborde bajo con inflexión hacia el exterior, a veces con un estrangulamiento bajo el labio); Vasos italianos de la serie de Popilius: borde colgante que a menudo se desmarca de la panza con una pequeña carena (Siebert, 1980, 58-59).

${ }^{13}$ Nos referimos a los conjuntos de cerámicas helenísticas de relieves presentes en El Monastil (Elda, Alicante) y en Cartagena. Destacamos también la existencia de un fragmento decorado con "liras, hojas de acanto y una greca" procedente del Tossal de Manises-Lucentum (Lafuente, 1959, 52, fig. 15).

${ }^{14}$ Se trata de siete fragmentos de borde, pertenecientes a cinco cuencos distintos (Tordera, 1991).

15 El fragmento en cuestión es la pieza $n^{\circ} 5$ del inventario realizado por P. Cabrera (Cabrera, 1979, 97), definido como un "fragmento de cuenco de perfil convexo y borde exvasado".

16 Sin embargo, debemos resaltar que a las 42 piezas publicadas por P. Cabrera (Cabrera, 1979) deben añadirse otras 31 piezas pertenecientes a las campañas de 1980 a 1985 , y una decena de piezas halladas en otros puntos de la ciudad, por lo que el conjunto eleva su número hasta casi el centenar (Pérez, 1991, nota 37). 


\begin{tabular}{|c|c|c|}
\hline DIÁMETRO $($ en $\mathrm{cm})$ & $\mathrm{N}^{\circ}$ de ejemplares & $\%$ \\
\hline 11 & 2 & $14^{\prime} 28$ \\
\hline 12 & 4 & $28^{\prime} 57$ \\
\hline 13 & 5 & $35^{\prime} 71$ \\
\hline $13^{\prime} 5$ & 1 & $7^{\prime} 14$ \\
\hline 14 & 2 & $14^{\prime} 28$ \\
\hline TOTAL & 14 & 100 \\
\hline
\end{tabular}

Figura 8: Tabla con diámetro de cuencos de La Alcudia.

ejemplares de Cartagena miden entre 11 y 15 cm (Cabrera, 1979, 98) y los de El Monastil entre 12 y $13 \mathrm{~cm}$ (Tordera, 1991, 20). Según esta información, podríamos reconstruir la altura de los vasos, aunque no contamos con ningún perfil completo que permita corroborar hipótesis sobre este aspecto ${ }^{17}$. Las bases proporcionan un tipo de información adicional, ya que en función de su aspecto liso o decorado se establece una diferenciación entre pequeños y grandes cuencos ${ }^{18}$, pero volvemos a encontrarnos con la dificultad del estado fragmentario y aislado de cada pieza. En los cuencos reconstruidos (LA-1018 y LA-1020) se aprecia que la relación establecida por Laumonier para los "grandes cuencos" no se ha cumplido en el ejemplar que presenta el fondo decorado con una roseta (LA-1020), mientras que LA-1018 sí parece cumplir la establecida para los "pequeños cuencos".

Destaca el predominio de cuencos cuyo diámetro es de 12 ó $13 \mathrm{~cm}$, pues estas dos medidas concentran el mayor número de ejemplares, con cuatro individuos de la primera medida y cinco de la segunda (Fig. 8). La coincidencia de nuevo con los ejemplares de El Monastil es significativa.

En lo referente a la pasta y los barnices, los cuencos hallados en La Alcudia presentan características bastante uniformes, con matices en su calidad y coloración.

A pesar de que resulta imprescindible la elaboración de los pertinentes análisis de arcillas para poder determinar la creación de grupos a los que luego adscribir propiedades o procedencias distintas, esta vía no se ha abordado de forma decidida aún, tal vez por el hecho de que el estudio de las decoraciones se ha convertido en un elemento decisivo a la hora de realizar la identificación del taller y, por tanto, su procedencia ${ }^{19}$. En el conjunto de piezas presentado hemos observado un predominio de las pastas de arcillas cuyo color oscila entre el rosado-anaranjado y varios tonos de rojo-anaranjado, de modo que del total de piezas en las que hemos podido observar la pasta, sólo dos presentan una coloración distinta. Se trata de las piezas LA-942, cuya pasta es depurada, con fracturas rectas y de color castaño claro, en la que se aprecia la presencia de pequeños desgrasantes de color negro, muy finos, así como una serie de puntos blancos; y LA-943, que muestra una pasta depurada de color gris. En el resto de las piezas se aprecian en mayor o menor medida desgrasantes micáceos y una serie de puntos blancos, identificables como desgrasantes calcáreos. Las pruebas analíticas realizadas (Fig. 9-13) han demostrado la existencia de una composición similar en los ejemplares analizados, a pesar de su atribución a talleres diversos, lo que indica su homogeneidad y origen similar, a pesar de que se haya argumentado la posible existencia de imitaciones locales ${ }^{20}$.

Respecto al barniz de las piezas ${ }^{21}$, podemos apreciar diferentes tonalidades y calidades, pasando de mate a brillo metálico en distintas zonas de la misma pieza. Los intentos de apreciar una evolución cronológica

\footnotetext{
${ }^{17}$ Laumonier estima que la altura de los vasos corresponde por lo general a una proporción de $1 / 2$ del diámetro para la altura en los pequeños cuencos, pero advierte que no es extraordinaria la aparición de vasos que no cumplen estas proporciones (Laumonier, 1977, 16).

18 Así tenemos que se entiende por "pequeños cuencos" aquellos que tienen una base sin decoración y su diámetro oscila entre $10^{\prime} 5$ y $12 \mathrm{~cm}$, siendo variable la altura de las piezas. Los "grandes cuencos" serian aquellos cuya base está decorada con una roseta y su diámetro oscila entre 15 y $19 \mathrm{~cm}$, aunque se reconoce la existencia de numerosas variantes en las dimensiones (Laumonier, 1977, 16).

${ }^{19}$ En este artículo incluimos la analítica de varios ejemplares del conjunto con la intención de que sirva a ulteriores estudios sobre estas producciones cerámicas. Consisten en el análisis de composición mediante microscopio electrónico de barrido, realizados en tres puntos de la pasta cerámica correspondientes a las superficies interna y externa y al núcleo de la pieza, que se indica con el $n^{\circ} 2$. Los análisis han sido realizados bajo la dirección de $D$. Andrés Amorós en la Planta Cero de la Facultad de Ciencias de la Universidad de Alicante.

${ }^{20}$ Destacamos la pieza LA-950 del conjunto de La Alcudia por las estrechas similitudes formales y técnicas con la pieza número 32 de Cartagena (Cabrera, 1979, 91 y 95), al tiempo que la existencia de otro fragmento de cuenco con barniz de reflejos violáceos, LA-3685. P. Cabrera destacaba la presencia en el conjunto de Cartagena de dos fragmentos con barniz violáceo brillante $\left(n^{\circ} 7,32\right)$, y otros cuyo color de barniz y de pasta, calidad y aspecto general son diferentes e inferiores a las del resto de los fragmentos estudiados $\left(n^{\circ} g\right.$ y 38 ), llegando a plantear que se trate de imitaciones (Cabrera, 1979, 95).

21 Algunos autores criticaron el empleo del término barniz para designar el acabado de las piezas, aunque debido a su empleo frecuente finalmente se ha generalizado (Laumonier, 1977).
} 


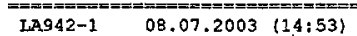

EO: $20.0 \mathrm{keV}$ (TO:35.0 TI:16.0)

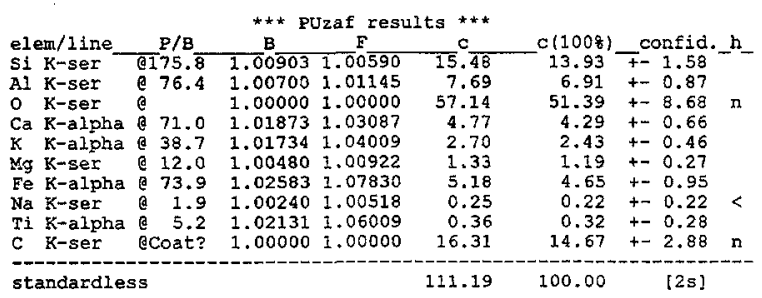

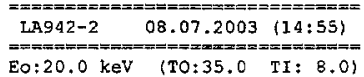

\begin{tabular}{|c|c|c|c|c|c|}
\hline elemiline & $\mathrm{P} / \mathrm{B}$ & ** PUzaf & & \multicolumn{2}{|c|}{$c(1008)$ confid. $h$} \\
\hline Si K-ser & 0178.5 & $1.00 \overline{9141.00589}$ & $\overline{15} . \overline{93}$ & -14.57 & +-1.75 \\
\hline AI $\mathrm{k}$-ser & a 75.8 & 1.007091 .01159 & 7.72 & 7.07 & +-0.95 \\
\hline o K-ser & & 1.000001 .00000 & 56.45 & 51.66 & +-8.74 \\
\hline Ca K-alpha & 72.4 & 1.018971 .03089 & 4. & 4.51 & +0.68 \\
\hline $\mathrm{K}$ K-ajpha & 38.3 & 1.017561 .04036 & 2.7 & 2.49 & +-0.45 \\
\hline Fe K-alpha & (e) 77.1 & 1.026171 .07594 & 5.49 & 5.03 & +-1.02 \\
\hline $\mathrm{Mg} \mathrm{K}$-ser & a 13.0 & $1.00486 \quad 1.00928$ & & 1.33 & +-0.29 \\
\hline Ti K-aipha & e 5.4 & 1.021591 .06013 & 0 . & 0.34 & +-0.26 \\
\hline C K-ser & ecoat? & 0001.00000 & 13.87 & 12.69 & +-2.55 \\
\hline Na K-ser & 2.5 & 431.00523 & 0.34 & 0.31 & +-0.23 \\
\hline sta & & & 1 & 100.00 & [2s] \\
\hline
\end{tabular}

\begin{tabular}{|c|c|c|}
\hline LA942-3 & 08.07 .2003 & $\{14: 59\}$ \\
\hline
\end{tabular}

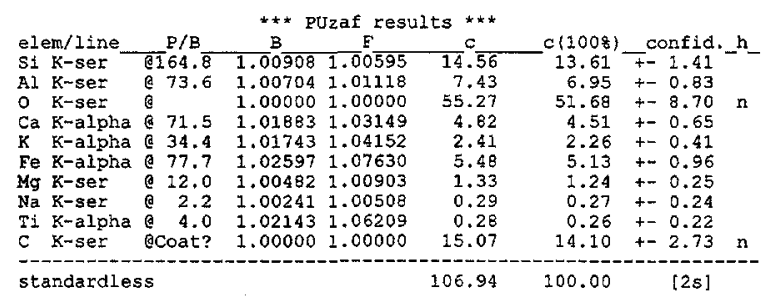

Figura 9: Análisis de composición de LA-942, perteneciente al taller del monograma.

en función del aspecto de los cuencos se han mostrado ineficaces ${ }^{22}$ debido a que no es una cuestión de cronología, sino de cocción ${ }^{23}$, como se ha puesto en relieve en diversos trabajos posteriores (Cabrera, 1979). Esta acción determina la coloración del barniz, que varía de un vaso a otro, e incluso dentro de un mismo vaso de una zona a otra, o del interior al exterior. Podemos encontrar barnices rojos a negros, con una relativa variedad de matices, pero generalmente existe una ecuación constante de color del barniz-color de la pasta, ya observada en otros conjuntos (Laumonier, 1977, 14; Goldman, 1950, 163). Así, a una pasta anaranjada le corresponde un barniz rojo claro o rojo fuerte, fruto de una cocción oxidante; a una pasta rosada-beige un barniz negro brillante
[24944-1 $08.07 .2003(15: 13)$

EO: $20.0 \mathrm{keV}$ (TO:35.0 TI:20.0)

$=2.994-2 \quad 08.07 .2003(15: 14)$

E0:20.0 keV (TO:35.0 TI:34.0)

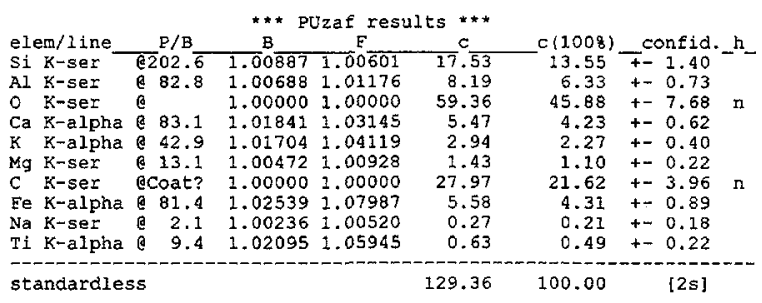

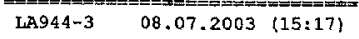

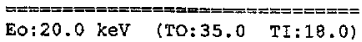

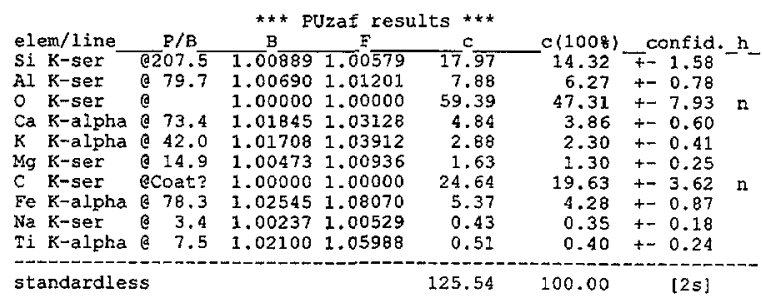

Figura 10: Análisis de composición de LA-944, perteneciente al taller del Cómico con bastón.

o marrón oscuro-negro debido a una cocción mixta; y a una pasta gris le corresponde siempre

\footnotetext{
22 A pesar de que en un primer momento se pensó que los cuencos con barniz brillante eran más antiguos que los de barniz mate (Courby, 1922, 281ss), y que éstos eran producciones exclusivas de ciertos talleres, esta rígida clasificación no es apropiada porque se ha demostrado que Courby generalizó el término barniz mate para distinguirlo del de los cuencos áticos con relieves de barniz más brillante (Laumonier, 1977). En realidad, hay toda clase de transiciones entre lo brillante y lo mate, incluso dentro de producciones del mismo taller.

23 "En fait il y a toutes sortes de transitions entre le glacé et le mat, et même entre le glacé noir attique et le glacé rouge dit pergaménien: c'est une question de cuisson" (Laumonier, $1977,15)$.
} 


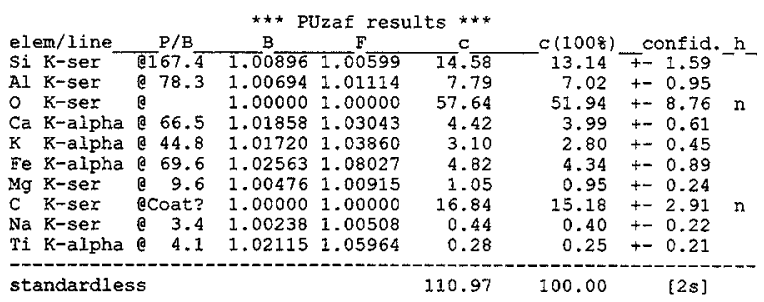

\section{RONTEC EDWIN WinTOOls}

version: 3.1 eng

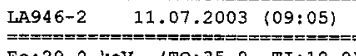

EO: $20.0 \mathrm{keV}$ (TO: 35.0 TI: 18.0 )

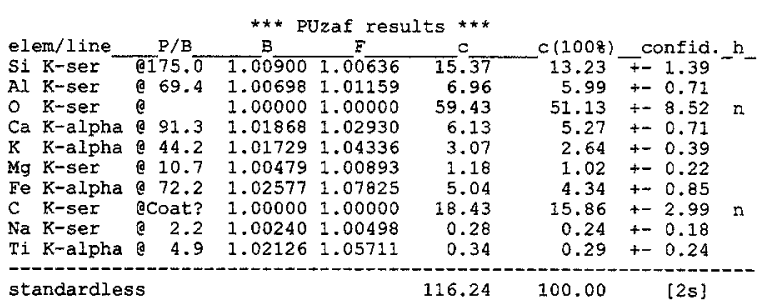

RONTEC EDWIN WinTOols

version: $3.1 \mathrm{eng}$

LA946-3 $\quad 11.07 .2003 \quad(09: 09)$

EO: $20.0 \mathrm{keV}$ (TO: 35.0 TI: 8.0 )

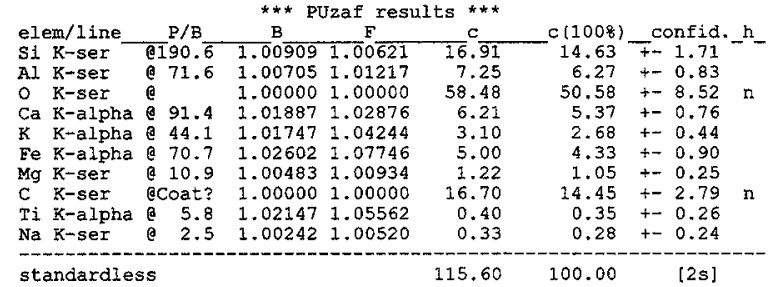

Figura 11: Análisis de composición de LA-946, perteneciente al taller de Philon.

un barniz negro, resultado de una cocción reductora.

\subsection{Decoraciones}

El conjunto analizado permite observar un nutrido elenco de motivos decorativos debido a que contamos con fragmentos pertenecientes a varias zonas de los cuencos. Si bien la decoración de la zona más próxima al borde se caracteriza por ser lisa, bajo ésta se dispone por lo general una franja que presenta motivos bastante estandarizados y difundidos. El resto de la pieza frecuentemente acoge un repertorio muy amplio de motivos, aunque debemos destacar la existencia de

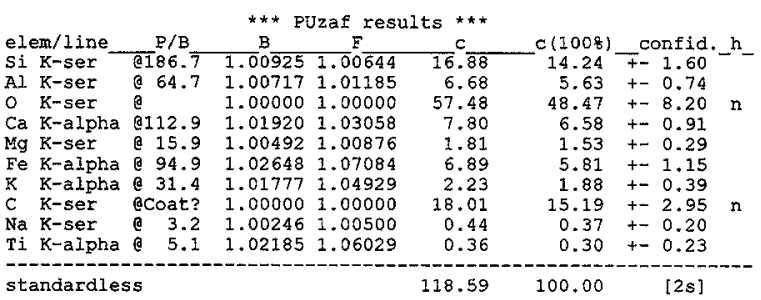

$==0$ RONTEC EDWIN WinToOls
$============-============$
version: 3.1 eng

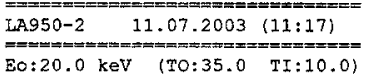

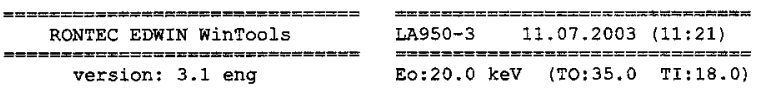

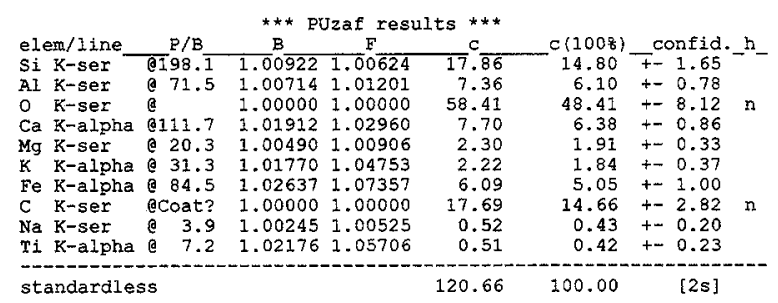

Figura 12: Análisis de composición de LA-950, perteneciente al taller de "decoración vegetal".

ejemplares con la base lisa y otros decorados en esta zona.

Como ya han puesto de manifiesto diferentes estudios, el elemento que mejor puede darnos un índice cronológico y un posible lugar de origen y fabricación es la decoración, más que la forma o las características técnicas, ya que es en este aspecto en el que los distintos talleres volcaron toda su imaginación en la elección, disposición, combinación y, sobre todo, realización de los motivos (Cabrera, 1979, 98). Laumonier ya demostró que no hubo ningún taller que fabricara cerámica de relieves en aquella isla, sino que toda la producción "délica" estudiada por Courby y por él mismo pertenecía a una serie de talleres originarios 


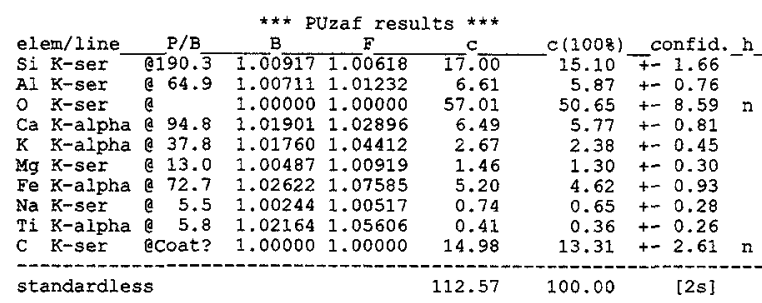

RONTEC EDWIN WinTOols

version: 3.1 eng

\begin{tabular}{|c|c|c|c|c|c|c|c|}
\hline & & $\star \star \star$ PL & Jzaf $\mathrm{re}$ & $\cdot 5 * \star *$ & & & \\
\hline lem/line & $\mathrm{P} /$ & B & $\mathrm{F}$ & & $c(1008)$ & confid. & \\
\hline K-ser & $8162 . \overline{1}$ & 1.00913 & $1.00 \overline{712}$ & $\overline{14} . \overline{44}$ & 12.85 & +-1.45 & \\
\hline $\mathrm{K}$-ser & 56.7 & 1.00708 & 1.01187 & 5.77 & 5.14 & +-0.68 & \\
\hline$K$-ser & a & 1.00000 & 1.00000 & 55.93 & 49.76 & +-8.45 & \\
\hline K-alpha & 0125.7 & 1.01894 & 1.02740 & 8.59 & 7.64 & +-0.99 & \\
\hline K-alpha & 37.1 & 1.01753 & 1.05214 & 2.60 & 2.31 & +-0.43 & \\
\hline$K-\operatorname{ser}$ & 10.5 & 1.00485 & 1.00867 & 2.18 & 1.05 & +-0.25 & \\
\hline K-alpha & อ 68.7 & 1.02613 & 1.07467 & 4.90 & 4.36 & +-0.91 & \\
\hline K-ser & ecoat? & 1.00000 & 1.00000 & 28.06 & 16.06 & +-3.11 & \\
\hline K-ser & 2.1 & 1.00243 & 1.00485 & 0.27 & 0.24 & +-0.22 & \\
\hline$k$-ser & 3.3 & 1.01281 & 1.0 & 0. & 0.22 & +-0.15 & \\
\hline K-alpha & 6.0 & 1.02156 & 1.05285 & 0.42 & 0.37 & $t-0.26$ & \\
\hline & & & & & & s) & \\
\hline
\end{tabular}

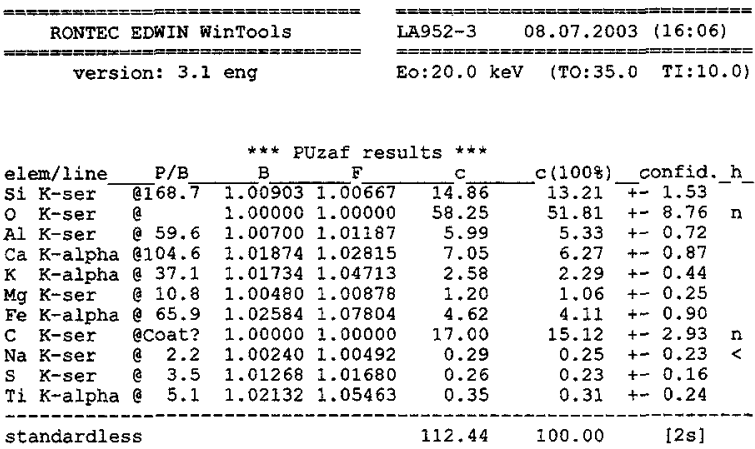

Figura 13: Análisis de LA-952, perteneciente al taller del monograma.

de Asia Menor, de la costa jonia (Laumonier, 1977). A este grupo de talleres jonios pertenecen los cuencos hallados en Cartagena (Cabrera, 1979) y El Monastil (Tordera, 1991).

Tras el análisis de los motivos que decoran la superficie de los cuencos de La Alcudia se han podido establecer distintos grupos a partir del taller originario (Fig. 14), circunstancia que permite observar una serie de cuestiones:

Por una parte, el alto número de fragmentos cuya atribución ha resultado complicada, por lo que han engrosado el grupo de "indeterminados" (11 ejemplares: LA-1039-19,

\begin{tabular}{|l|c|c|}
\hline \multicolumn{1}{|c|}{ TALLER } & N $^{\circ}$ EJEMPLARES & $\%$ \\
\hline monograma & 13 & $41^{\prime} 93$ \\
\hline Menémakhos & 3 & $9^{\prime} 67$ \\
\hline Philon & 2 & $6^{\prime} 45$ \\
\hline Cómico con bastón & 1 & $3^{\prime} 22$ \\
\hline «decoración vegetal» & 1 & $3^{\prime} 22$ \\
\hline indeterminados & 11 & $35^{\prime} 48$ \\
\hline \multicolumn{1}{|c|}{ TOTAL } & 31 & 100 \\
\hline
\end{tabular}

Figura 14: Tabla con los talleres identificados.

LA-499, LA-953, LA-954, LA-955, LA-956, LA957, LA-960, LA-1018, SIN No (2), LA-3685), debido al reducido tamaño de los fragmentos o a la existencia de varios talleres que produjeron motivos decorativos similares.

Por otra, el predominio de los cuencos producidos en el taller del monograma, que con 13 ejemplares (LA-941, LA-942, LA-943, LA945, LA-947, LA-951, LA-952, LA-958, LA-959, LA-961, LA-1020, LA-1700, LA-2470) es el mayor de los grupos examinados. El segundo grupo por número de ejemplares lo constituye el correspondiente a las piezas englobadas como producciones del taller de Menémakhos, al que pertenecen LA-949, LA-1020 y SIN N ${ }^{\circ}$ (1). En el grupo correspondiente al taller de Philon hemos diferenciado dos ejemplares (LA946, LA-948), mientras que el taller del Cómico con bastón (LA-944) y el grupo "decoración vegetal" (LA-950) muestran un ejemplar cada uno. Esta circunstancia no debe extrañarnos a la luz de la información proporcionada por otros lugares donde se ha encontrado este tipo de material cerámico, ya que las cifras muestran un predominio del taller del monograma, seguido por el de Menémakhos, como sucede en Cartagena (Cabrera, 1979, 103; Pérez, 1994, 354) y otros puntos del Mediterráneo occidental.

Finalmente, la variedad del repertorio decorativo de las piezas examinadas, ya que hemos podido diferenciar hasta 23 motivos distintos (Fig. 15), donde predominan varias clases de elementos vegetales. Encontramos también bases lisas (LA-948, LA-950, LA-1018) y en las decoradas (LA-946, LA-1020, LA-2470) se ha empleado de forma mayoritaria el recurso a la roseta de grandes dimensiones, diferenciando unas con extremos redondeados y otras con los pétalos alargados y puntiagudos.

No existen por el momento evidencias de que los punzones aparecidos en La Alcudia fuesen empleados sobre tipos cerámicos concretos, ya que entre las piezas analizadas ninguna permite atribuir una posible vinculación con sus impresiones. Además, el contexto en que aparecieron no corresponde, a priori, a la 
imagen de un taller de producción cerámica ${ }^{24}$ Según comunica su excavador, el espacio perteneciente al ángulo noroeste de este edificio, comprendido entre la mesa de ofrendas y las paredes oeste y norte, así como el fondo de la cámara subterránea, aportaron abundante material cerámico, perteneciente a finales del siglo III y finales del siglo I a.C. (Ramos Fernández, 1995, 10).

Los motivos decorativos de estos punzones remiten al lenguaje iconográfico que transmiten las cerámicas de relieves helenísticas, pues existen decoraciones en las que se alternan cabezas de bóvidos y guirnaldas también presentes en el yacimiento - y en el fondo de los denominados "grandes vasos" se representa de forma habitual una roseta en el centro (Laumonier, 1977, 16), cuya presencia en el molde o punzón de La Alcudia es innegable. Existen mayores dificultades de clasificación para este motivo, pues si para la cabeza de bóvido conocemos modelos similares en cuencos procedentes de talleres jonios ${ }^{25}$, la gran difusión de los motivos vegetales dificulta una atribución precisa ${ }^{26}$.

\section{CRONOLOGÍA DEL CONJUNTO}

En lo referente a la cerámica decorada con relieves a molde, sólo las lucernas y los cuencos han sido estudiados con detalle. Los

\begin{abstract}
24 Este espacio ha sido interpretado por Ramos como lugar de culto vinculable a los círculos de Tanit/Artemis/Deméter y dos dioses: uno adulto - su consorte, "el señor de la tierra", el caballo -, y otro joven - hijo y víctima, el toro-, que podrían relacionarse con Poseidas y Sabazios (Ramos Fernández,1995; 1997). Otros autores apuntan versiones similares vinculadas con la diosa protectora de la ciudad (Almagro - Gorbea y Moneo, 2000).

${ }_{25}$ Podemos destacar la existencia de este motivo en los cuencos estudiados y atribuidos a diversos talleres jonios en Laumonier, 1977, cómico con bastón: PI. 26, 1111; taller del monograma: PI. 39, 8747; Heraios: PI. 129, 3481.

${ }^{26}$ A pesar de ello, es probable que pertenezca al grupo de repertorios decorativos empleados en las bases por el taller de Philon, pues son caracteristicas de este taller las rosetas de ocho pétalos grandes y redondeados dentro de las que se realiza otra de menores dimensiones, rodeándolas con una sucesión de hojas de acanto y lanceoladas dispuestas de forma radial en número de cuatro de cada tipo (Laumonier, 1977, PI. 62, 670; PI. 63, 8675). Recordemos además la existencia de cuencos procedentes de este taller en el yacimiento, cuyos fragmentos han sido examinados en este estudio (LA-946, LA-948).
\end{abstract}

\begin{tabular}{|c|c|c|c|}
\hline MOTIVO DECORATIVO & $\mathrm{N}^{\circ} \mathrm{CASOS}$ & $N^{\circ}$ INVENTARIO & TALLER \\
\hline Roseta de 8 pétalos & 4 & $\begin{array}{l}\text { LA-941, LA-945, LA,947, LA- } \\
958\end{array}$ & Menémakhos, monograma \\
\hline Roseta de 7 pétalos & 3 & LA-942, LA-943, LA-954 & monograma \\
\hline "Bastoncillos" con punto & 1 & LA-943 & monograma, Cómico con bastón \\
\hline Ovas y dardos & 3 & LA-951, LA-1700, LA-945 & monograma, generalizado \\
\hline Banda de "S" vertical & 2 & LA-961, LA-1020 & monograma \\
\hline Banda de "S" horizontal & 2 & LA-941, LA-952 & Menémakhos, monograma \\
\hline Volutas vegetales & 1 & LA-942 & monograma \\
\hline Hojas de acanto & 3 & LA-942, LA-945, LA-956 & monograma, generalizado \\
\hline Palmetas de 7 hojas & 1 & LA-944 & Cómico con bastón \\
\hline Palmetas de 5 hojas & 1 & LA-948 & Philon \\
\hline "Torsade" & 1 & LA-944 & Cómico con bastón \\
\hline Hojas imbricadas & 3 & LA-952, LA-961, LA-1018 & monograma \\
\hline Contario & 2 & LA-945, LA-947 & monograma \\
\hline Hojas de helecho o palmas & 2 & LA-946, LA-950 & Philon, "decoración vegetal" \\
\hline Hojas lanceoladas lisas & 2 & LA-946, LA-1020 & Philon \\
\hline Capullos vegetales & 3 & LA-947, LA-951, LA-959 & monograma \\
\hline "Lazos", astrágalos o carretes & 1 & LA-949 & Menémakhos \\
\hline $\begin{array}{l}\text { Esvásticas, meandros con rosetas dentro } \\
\text { de cuadrado }\end{array}$ & 2 & LA-952, LA'99/TO/1039/19 & Menémakhos, monograma \\
\hline Entrelazados & 1 & LA-955 & generalizado \\
\hline Bucráneos y guirnaldas & 1 & LA-957 & $\begin{array}{l}\text { Cómico con bastón, } \\
\text { monograma, Heraios }\end{array}$ \\
\hline Róleos vegetales & 1 & LA-1018 & $\begin{array}{c}\text { Menémakhos, "estrellas de } 6 \\
\text { brazos ahuecadas", "pequeña } \\
\text { rosa en espiral" }\end{array}$ \\
\hline Agrupaciones de 3 puntos & 1 & LA-1020 & Menémakhos \\
\hline Molduras ovaladas, "godrones" & 1 & LA-3685 & generalizado \\
\hline Olas, ondas & 1 & LA-953 & Menémakhos, monograma \\
\hline
\end{tabular}

Fig. 15: Tabla con los motivos decorativos. 
primeros ejemplos del empleo de una decoración a molde se remontan en Ática justo antes de mediados del siglo III a.C. con las lucernas de la forma Howland $42 \mathrm{~A}$ y $\mathrm{B}$. Las formas más elaboradas serían influenciadas por las importaciones ${ }^{27}$ y son contemporáneas al apogeo de los cuencos de relieves a molde (Rotroff, 1982). En absoluto se excluye que ciertos talleres continúen fabricando tanto vasos como lucernas, como ya se ha establecido para las cerámicas a torno de los períodos anteriores (Blondé, 2001, 35).

Para los cuencos con relieves, los contextos, las evidencias históricas y los prototipos en vidrio y metal permiten situar los primeros ejemplares de Atenas en torno al 225 a.C. Para el primer período (225-150/140 a.C.), Rotroff distingue 7 grupos, de los que algunos corresponden a los talleres de "Bion" o "Atelier A" (Blondé, 2001, 35). Poco después de mediados del siglo II a.C., la producción de la mayor parte de los tipos de cuencos se detiene, salvo para la de cuencos con decoración imbricada. A partir de este período y hasta aproximadamente el 80 a.C. ${ }^{28}$, los cuencos con decoración de godrones o relieves serán los más representados, inspirados, asimismo, por los prototipos en metal ${ }^{29}$. Los productos atenienses de esta categoria están presentes en una gran extensión geográfica, pero en pequeña cantidad (Blondé, 2001, 38), pues las imitaciones toman el relevo con fuerza.

Así nacen talleres que producen estas cerámicas en diversos puntos del Mediterráneo, como sucede en la Península Itálica. Allí debieron tener bastante éxito, como denota la existencia de talleres propios en Etruria, Lacio y Apulia, que fabricaron los llamados cuencos "ítalo-megáricos" (Morel, 1976, 486, nota 45). La cronología de estas producciones es un debate abierto, pues sus dataciones oscilan entre mediados del siglo III y finales del siglo I a.C. (Morel, 1976, 487, nota 46). Sin embargo, los cuencos que encontramos en las costas occidentales del Mediterráneo proceden mayoritariamente de talleres de origen jonio, muy abundantes en Delos entre la mitad del siglo II y los dos primeros decenios del siglo I a.C. (Laumonier, 1962 y 1977; Pérez, 1994, 352).

Sirve como ejemplo el sur de Francia, donde encontramos una decena de lugares con hallazgos de cerámicas helenísticas de relieves, en algunos casos pecios, como el Grand Congloué, con 13 fragmentos pertenecientes al menos a dos cuencos distintos; o en el Mediterráneo Central, donde el pecio de Spargi (120/100 a.C.) ha proporcionado 16 fragmentos de cuencos pertenecientes a cuatro piezas. El resto se encuentra ya en yacimientos de la costa del Midi, o en oppida indígenas cercanos a ella, siempre en pequeño número, entre 1 y 6 fragmentos por lugar. Excepciones a la regla son Toulouse - con una cuarentena de fragmentos no publicados -, y la presumible abundancia de Marsella, donde sólo conocemos alguna mención aislada (Pérez, 1994, 352). La datación de este tipo de piezas cerámicas en lugares como Lattes presenta un marco cronológico muy amplio, entre el 250 y el 25 a.C. (Py, 1993, 132-133), aunque un estudio reciente del conjunto (Py et alii, 2001) ha afinado las cronologías, ahora centradas entre finales del siglo II a.C. y principios del siglo I a.C. ${ }^{30}$

El número de hallazgos de estas cerámicas en la Península Ibérica revela un panorama muy significativo, ya que encontramos una amplia concentración de cuencos en las regiones de Murcia y Alicante, y otro importante foco en las islas Baleares. En el primer caso, la presencia de las cerámicas de este tipo y otros elementos de origen sur-itálico y oriental de época helenística ha sido puesta en relación con la importancia del activo puerto comercial de Carthago Nova ${ }^{31}$. La datación para este conjunto de casi un centenar de piezas ha

27 Es el caso de la forma Howland tipo $45 \mathrm{~A}$, con fecha de introducción cercana al 260 a.C.

${ }^{28}$ Para los cuencos con decoraciones de godrones o relieve en los que su datación es un problema, la presencia habitual de este tipo antes del 146 a.C. en Atenas y en Carthago puede proporcionar los indicios. K. Slane (AJA 88 [1984], 614-615) no excluye que el origen de este tipo se encuentre en Corinto (Blondé, 2001, nota 31).

${ }^{29}$ Como apunta Blondé, el estudio paralelo de vasos en vidrio, fayenza y en metal, ya iniciado con los primeros estudios, es un campo en el que se debe profundizar por completo, porque es muy rico en posibilidades para la cerámica helenística (Blondé, 2001).

${ }^{30}$ La opinión expresada por estos autores muestra que la llegada de cerámicas de este tipo se produce de forma restringida a las costas del Mediterráneo occidental: "quelques dizaines de pièces seulement ont été signalées en France et en Espagne" (Py et alii, 2001, 417); hecho que los hallazgos de Cartagena obligarian a matizar. Del mismo modo, la datación se realiza mediante la asociación de materiales datantes aparecidos junto a los ejemplares, dándose la circunstancia que dos de los 5 fragmentos aparecidos se datan por contexto entre el 75/50 a.C.

31 Sobre la importancia del puerto de Carthago Nova y las evidencias de importaciones orientales existe una dilatada bibliografía. Entre otros, podemos citar: Ramallo, 1989, 5053; 1993; Ramallo y Ruiz, 1994; Pérez, 1983, 1994, 2002. 
sido establecida a fines del siglo II a.C. (Cabrera, 1979, 103-104), momento de mayor actividad de los talleres jonios, fecha confirmada para el Mediterráneo Occidental por los hallazgos de Pollentia (130-60 a.C.), por los de Entremont (125 a.C.) y por los del Grand Clongloué (150-30 a.C.). En las Islas Baleares su presencia se debe esencialmente a la existencia de las colonias romanas de Pollentia y Palma, fundadas ambas entre 123 y 120 a.C.(Pérez, 1994, 353). En cuanto a su distribución ${ }^{32}$, los cuencos de relieves se reparten entre la propia Pollentia y zonas de necrópolis o santuarios, con una datación similar a la ofrecida para Cartagena. Un caso particular es la datación ofrecida para el pecio de S. Jordi (Mallorca), entre 100/80 a.C.

En Ampurias su representación es muy escasa (Vegas, 1953-1954), aunque destaca la presencia de un fragmento de molde cuya atribución posiblemente corresponda a una pieza perteneciente a un vaso "ítalo-megárico" (Vegas, 1955-1956; Pérez, 1994, 352-353).

Las condiciones en que el conjunto de materiales de La Alcudia fue formado, fruto de excavaciones antiguas en las que sólo se adscribió el tipo cerámico a un nivel arqueológico, y la aparición de fragmentos en las últimas excavaciones como materiales residuales o rodados en unidades estratigráficas superficiales o de relleno, han sesgado las posibilidades de ofrecer un contexto estratigráfico claro y preciso, por lo que sólo podemos ofrecer una datación por criterios estilísticos. Las características propias de estos cuencos los vinculan de forma directa con piezas existentes en los conjuntos de Cartagena y El Monastil, por lo que sin duda deberán fecharse dentro del mismo arco cronológico, es decir, a finales del siglo II a.C. o principios del siglo I a.C.

\section{VALORACIÓN}

La presencia de cerámicas helenísticas de relieves y su asociación a otros vasos y contenedores ha sido objeto de interpretaciones que las vinculan con cierto tipo de comercio de vino (Pérez, 1994, 350), en un radio de distribución que desde Oriente llega a las costas del Mediterráneo occidental. No extraña por ello que sea en Cartagena donde se produzca la aparición del mayor conjunto de cerámicas de este tipo del Mediterráneo occidental ${ }^{33}$ junto a lagynoi de engobe blanco, ánforas rodias, sigillatas orientales y otras manifestaciones de un lenguaje helenístico con paralelos formales muy claros en el Mediterráneo oriental ${ }^{34}$. Su capacidad de atracción de gentes y productos residirá en la actividad y los beneficios que emanan de la explotación de las minas. Sin embargo, a pesar de que el puerto es romano ya en fechas tempranas y su capacidad para ser centro de recepción y salida de productos es indiscutible, no encontramos evidencias de actividad en los territorios ubicados al Norte de Carthago Nova hasta mediados - finales del siglo II a.C., hecho que ha suscitado más de una reflexión al respecto ${ }^{35}$, pues la actividad detectada se concentra fundamentalmente en torno a las fechas del conflicto Sertoriano.

El conocimiento que poseemos de La Alcudia para estas fechas se encuentra en un proceso de reestudio en la actualidad. La presencia de los elementos que constituyen el "nivel E” o "ibérico II" (Ramos Fernández, 1975,

\footnotetext{
32 M. Beltrán (Beltrán, 1990, 61) recoge varias publicaciones en las que se aborda el estudio de cerámicas de relieves aparecidas en Baleares: Arribas, A.-Tarradell, M.-Woods, D., 1978: "Excavaciones en Sa Portella, Alcudia, Mallorca", EAE, 98, Madrid, 59; Arribas, A.-Trías, G., 1959: "Cerámica de Megara en Pollentia, Alcudia, Mallorca“, AEA, XXXII, 84 ss.; Cerda, D., 1980: La nave romano-republicana de la colonia de Sant Jordi Ses Salines - Mallorca, Palma de Mallorca, 34; Colls, D., 1987: "L'epave de la colonia de Sant Jordi , (Majorque)", PCPP, 16, Paris, 57.

33 Circunstancia que no ha sido reflejada en estudios de cerámicas de este tipo realizados recientemente. Véase Py et alii, 2001, 417.
}

${ }^{34}$ Nos referimos entre otros a la existencia de un edículo de época republicana dedicado a Atargatis, divinidad oriental, y a manifestaciones arquitectónicas en todo el territorio que remiten a influencias helenisticas (Ramallo y Ruiz, 1994).

${ }_{35}$ Sobresale, por la actualización de los datos que introduce, el estudio realizado por $F$. Sala donde establece un panorama del poblamiento contestano en el siglo III a.C. a través del análisis de los contextos cerámicos (Sala, 1998, 47). Debemos añadir las líneas emanadas de un trabajo sobre el poblamiento en la comarca del Bajo Segura (Gutiérrez et alii, 1998-1999, 60-61) que inciden de nuevo en esta situación: "Les indices d'une occupation de la vallée sont infiniment plus rares après qu'avant la conquête romaine. L'époque républicaine (lle et jer siècles av. J.-C.) est particulièrement pauvre en vestiges, ce qui contraste fortement avec la densité d'habitat des $I^{*}$ et $I I^{\prime}$ siècles. Les seuls sites ayant livré des traces d'une occupation républicaine sont le Castillo de Guardamar (fragments de campanienne dans le sondage A 1b: Abad, 1992, 227), le petit établissement rural de Los Tintoreros (site 4: un fragment de campanienne) et La Escuera dans la phase qui précède son abandon définitif dans la première moitié du $l^{\circ}$ siècle (Sala, 1996, 216). Tout porte à croire que de nombreux sites d'habitat sont abandonés au lendemain de la conquête, très probablement au profit de La Alcudia de Elche qui connait alors une phase de grande prospérité". 
129-147) del yacimiento conduce de forma mayoritaria a dataciones posteriores a la Segunda Guerra Púnica, siendo muy destacable el baile de cronologías que se ha producido en otros yacimientos cercanos, como el Tossal de Manises - Lucentum (Olcina, 2002). De este modo, muchos de los elementos que se consideraban en la historiografía del yacimiento ilicitano como definitorios de un momento de influencias del mundo cartaginés, pertenecen a un momento posterior a la conquista del territorio y a la presencia romana ${ }^{36}$. Es el caso de la cerámica de relieves, que pasa a mostrarse como otro elemento que refleja la influencia del centro comercial de mayor entidad en las proximidades ${ }^{37}$, Carthago Nova, pues hasta aquí llegan manifestaciones tan significativas como el mosaico de "Sailacos" y pavimentos de signinum con retícula de rombos (Ramos Folqués, 1975; Ramos Fernández, 1975; Abad, 1987; Fernández Díaz, 2003), que evidencian un alto nivel de asimilación del gusto helenístico y conocimiento de las técnicas empleadas ${ }^{38}$. Junto a ellos debemos valorar la presencia de influencias visibles en la decoración pintada vascular (Ros, $1989,132-137$ ), la existencia de varios fragmentos de lagynoi de engobe blanco ${ }^{39}$, ánforas rodias (Pérez, 1994), cerámica de Gnatia (Pérez, 2002, 38), cuencos de relieves $y$, al menos, un fragmento de sigillata oriental ${ }^{40}$. A todo ello debemos añadir que el estudio del contexto constituido por la denominada "tienda del alfarero" (Sala, 1992, 198) proporciona una datación de finales del siglo II - principios del siglo I a.C. para piezas del estilo figurado de Elche, en un momento ya romano e influenciado por todos los elementos que de una forma $u$ otra fueron interpretados e integrados a los repertorios propios de los iberos.

Si como sucede en Lattes ( $P y$ et alii, 2002), los contextos permitiesen ofrecer una datación más ajustada y cercana al arco temporal que alli se baraja para diversos fragmentos, entre el 100-50 a.C., la explicación

\footnotetext{
${ }^{36} \mathrm{E}$. Llobregat realizó una serie de reflexiones críticas sobre la necesidad de establecer unos márgenes cronológicos precisos para los "niveles" de La Alcudia (Llobregat, 1972, 79-85). F. Sala y M. Olcina inciden de nuevo sobre este aspecto (Olcina y Sala, 2000, 109), pues "a la vista de esta heterogeneidad de materiales es evidente que el "nivel E" no se corresponde con una entidad estratigráfica única, sino que debe englobar diversas fases, o bien puede suceder que la presencia de los materiales más antiguos sea residual $y$, en este caso, habría que corregir la datación del periodo. También ocurre que los niveles $E$ y $D$ se solapan casi en
}

todo el siglo I a.C.. Por todo ello, y pese a que La Alcudia ofrece un buen lote de vasos de barniz negro, en este yacimiento queda excluido por el momento cualquier intento de determinar contextos; ni tan siquiera es posible proponer dataciones para los flujos de mercado, aparición-desaparición de ciertos productos y sus porcentajes".

37 Destaca el lote de cerámicas de relieves existente en El Monastil (Elda), que F.F. Tordera relaciona con una penetración hacia el valle medio del Vinalopó a través de una ruta que conecta el Bajo Segura, la Serra de Crevillent y este asentamiento (Tordera, 1991, 25-27). También pudo funcionar la ruta que atraviesa el litoral hasta La Alcudia, y desde alli hacia el interior, siguiendo el curso del río, aunque la conexión del puerto de Lucentum con el asentamiento de La Alcudia agilizaría la difusión de mercancias procedentes de otros puntos cercanos.

${ }^{38}$ En los últimos años se han desarrollado estudios en esta línea de investigación, centrados en el conocimiento de aspectos técnicos y formales, para de este modo determinar los ritmos de llegada de las influencias. Para los mosaicos y pinturas: Ramallo, 2001; Fernández Díaz, 2003.

${ }^{39}$ La identificación de las piezas (Pérez et alii, 1980,155164, fig. 4) destaca la presencia de dos fragmentos posiblemente fabricados en Pérgamo en las vitrinas del Museo Monográfico de La Alcudia. En la actualidad pueden contemplarse con $n^{\circ}$ de inventario LA-1038 y LA-1044.

${ }^{40}$ La identificación de esta producción es fruto de la revisión de los fondos, donde se ha detectado la presencia de un fragmento de borde de sigillata oriental del tipo A, procedente de la excavación del "templo ibérico" y depositado con $n^{\circ}$ de inventario LA-3684 (Fig. 4, 9). El citado fragmento se caracteriza por presentar una pasta de color rosadoanaranjado, con desgrasante micáceo muy fino, mientras que la superficie de la pieza presenta un color que oscila entre el naranja y el castaño claro. Posiblemente fue este rasgo el que propició su identificación como un "fragmento de borde de plato de sigillata aretina" (Ramos Fernández, 1995, 96 , Fig. 665), pero la presencia de desgrasantes micáceos no es frecuente en las producciones aretinas, y la forma representada no aparece en el repertorio formal de esas mismas producciones (Ettlinger et alii, 1990). La decoración del fragmento la constituyen una serie de puntos en resalte sobre la superficie del borde y una serie de motivos similares a granadas estilizadas junto a ellos. En la parte colgante del labio no presenta decoración. Fue Kenyon (Kenyon, 1957, 281 ss.) quien estableció la tipología fundamental de estas cerámicas, de forma que debemos incluir el fragmento de La Alcudia en el primero de sus grupos (Eastern Sigillata A) debido a las estrechas similitudes que presentan. La cronología que se ofrece nos remite en Samaria a los años 86-60 a.C., pudiendo alcanzar fechas en torno al 30 a.C., dándose la circunstancia de que en el "estrato pre-Herodiano" están presentes fragmentos de cerámicas de relieves helenísticas (Kenyon, 1954, 289). El fragmento hallado en La Alcudia presenta muchas similitudes con los perfiles que ofrecen las formas 7-9, una serie de platos de dimensiones variables - el diámetro de la pieza que presentamos oscila entre 34-36 cm-, aunque no muestra la decoración característica de ovas y dardos en la parte coigante del labio, oscilando la cronologia de estas piezas entre mediados del siglo I a.C. y finales del siglo I a.C. (Hayes, 1985, 18, tav. II, 7-9). Resulta muy significativo este dato, al que debemos añadir la presencia dè al menos dos fragmentos de este tipo de productos cerámicos en Cartagena (Pérez, 1983), puerto receptor desde el que pudo llegar la pieza en cuestión hasta La Alcudia junto a los ya mencionados cuencos de relieves. 
tal vez debería interpretar la llegada de los elementos destacados como resultado del cambio de actitud de la política romana hacia los territorios contestanos en el marco del enfrentamiento contra Sertorio y los sucesos inmediatos, pues aquí se establece un notable contingente de población favorable (recordemos que Dianium se convierte en sede de su flota). Cuestiones que plantean una incorporación rápida a los influjos del helenismo tardío y a la órbita de Roma, tal vez fruto de la presencia militar, atestiguada en el Tossal de Manises ${ }^{41}$, que probablemente permitió controlar la estabilidad del territorio entre este punto y Carthago Nova.

\author{
Gabriel Lara Vives \\ Area de Arqueología \\ Dpto. de Prehistoria, Arqueología, \\ $\mathrm{H}^{\mathrm{a}}$ Antigua, Filología Griega y \\ Filología Latina \\ Facultad de Filosofía y Letras \\ Universidad de Alicante \\ Apdo. 99 \\ 03080 Alicante \\ gabriel.lara@ua.es
}

\section{BIBLIOGRAFÍA}

ABAD CASAL, L., 1987: "En torno a dos mosaicos ilicitanos: el "helenístico" y el de conchas marinas", Homenaje al Prof. Gratiniano Nieto, vol. II; Cuadernos de Prehistoria y Arqueología, 13-14, 97-105.

ABAD CASAL, L. et alii, 2001: "La Escuera", Poblamiento Ibérico en el Bajo Segura: El Oral (II) y La Escuera, Madrid.

ALMAGRO - GORBEA y MONEO, T., 2000: Santuarios Urbanos en el mundo ibérico, Madrid.

BELTRÁN, M., 1990: Guía de la cerámica romana, Zaragoza.

BENOIT, M. F., 1947: "Recherches archéologiques dans la région d'Aix-en-Provence (Bouches-du-Rhône)», Gallia, $V$, fasc. 1, 81-122.

BLONDÉ, F., 2001: "La céramique attique hellénistique à vernis noir: quelques commentaires sur les acquis récents et les problèmes", Céramiques hellénistiques et romaines, III, 31-55, París.

CABRERA BONET, P., 1978-1979: "La cerámica helenística de relieves de Cartagena", Cuadernos de Prehistoria y Arqueología de la Universidad Autónoma de Madrid, 5-6, 81-104.

CABRERA BONET, P., 2004: "La cerámica helenística de relieves de La Alcudia (Elche)", El yacimiento de $L a$ Alcudia: pasado y presente de un enclave ibérico, Anejos de AEspA, XXX, p. 55-69, Madrid.

COURBY, F., 1922: Les vases grecs à reliefs, París.

ETTLINGER, E. et alii, 1990: Conspectus Formarum Terra Sigillata Italico Modo Confectae, Bonn.

FERNÁNDEZ DE AVILÉS, A., 1957: "Cerámica de Megara en Espanha", Revista Guimarâes, LXVII, 1-2, 47- 54.
FERNÁNDEZ DÍAZ, A., 2003: "Adopción de las técnicas pictóricas y musivarias entre las socidades iberas", De Iberia in Hispaniam: La adaptación de las sociedades ibéricas a los modelos romanos (Soria 2002), 211-239, Alicante.

GOLDMAN, H. 1950: Excavations at Gözul Kule. Tarsus I. The Hellenistic and Roman Periods, Princeton University Press.

GUTIÉRREZ LLORET, S., MORET, P., ROUILLARD, P. y SILLIĖRES, P., 1998-1999: "Le peuplement du Bas Segura de la Protohistoire au Moyen Âge (Prospections 1989-1990)", Lucentum, XVII-XVIII , 25-74.

HAYES, J.W., 1985: "Sigillata orientale A (Eastern sigillata A)", Atlante delle forme ceramiche.ll : Ceramica fine romana nel bacino Mediterraneo (tardo elenismo e primo impero), 9-47, Roma.

KENYON, J., 1957: "The objets from Samaria", SamariaSebaste, vol. III : Roman and later Wares. I - Terra sigillata, Londres.

LAFUENTE VIDAL, J., 1959: El Museo Arqueológico Provincial de Alicante. Catálogo-guia, Alicante.

LAUMONIER, A., 1962: "Bols hellénistiques à reliefs en Espagne", R.E.A., LXIV, 43-47.

LAUMONIER, A., 1977: La céramique hellénistique à reliefs. I: Ateliers “ioniens", Exploration Archéologique de Délos, XXXI, París.

LLOBREGAT CONESA, E., 1972: Contestania ibérica, Alicante.

MOREL, J.-P., 1976: "Céramiques d'Italie et céramiques hellénistiques (150-30 av.J.-C.)", Hellenismus in Mittelitalien, II, 471-501, Göttingen.

OLCINA DOMÈNECH, M. H., 2002: "Lucentum", Valencia y las primeras ciudades romanas de Hispania, 255-266, Valencia.

OLCINA DOMĖNECH, M.H. y SALA SELLÉS, F., 2000: "Las cerámicas de barniz negro en el área sur alicantina", $L a$ ceràmica de vernis negre del segles $/ /$ il a.C. : Centres productors mediterranis i caracterizació a la Península Ibèrica, Taula Rodona (Empúries, 4-5 juny de 1998), 107127. Mataró.

PÉREZ BALLESTER, J., CABRERA BONET, P. y PELÁEZ, N., 1980: "Noticia sobre cerámicas helenísticas de engobe blanco del tipo lagynos halladas en Cartagena", $M M, 21$, 155-164.

PÉREZ BALLESTER, J., 1983: "Cerámicas helenísticas del Mediterráneo oriental en Cartagena", XVI C.N.A. (MurciaCartagena 1982), 519-532, Zaragoza.

PÉREZ BALLESTER, J., 1994: "Asociaciones de laginos, boles helenísticos de relieves y ánforas rodias en contextos mediterráneos (siglos II y l a.C.)", Huelva arqueológica, XIII, 2, 345-365.

PÉREZ BALLESTER, J., 2002: Vasos sobrepintados italiotas del Museo Arqueológico Nacional de Madrid, Murcia.

\footnotetext{
${ }^{41}$ Olcina, 2002, 259-260: "Ios pocos materiales arqueológicos recuperados en los rellenos de algunas torres y los hallados en los escasos estratos del tramo $V$ relacionables con esta fase, nos dan una fecha de finales del siglo II a.C. y principios del siglo I a.C.: fragmentos de campanienses $A$, un ejemplar de $B$ etrusca, campaniense $B$ (calena media o círculo de la $B$ ), algunas B-oides (calenas tardías), e itálica de cocina con formas de segunda mitad del segundo y primera mitad del siglo l a.C.". El mismo autor plantea la posibilidad de vincular la creación de esta fortificación en el contexto de las luchas Sertorianas.
} 
POVEDA NAVARRO, A. M., 1988: El poblado ibero-romano de "ElMonastil" (Elda, Alicante). Introducción históricoarqueológica, Alicante.

PY, M., 1993: "Bols hellénistiques à reliefs", Lattara, 6, 132133.

PY, M., ADROHER AUROUX, A.M. y SÁNCHEZ, C., 2001: "Bols hellénistiques à reliefs", Corpus de céramiques de l'Àge du Fer de Lattes (fouilles 1963-1999), 1, 417-419.

RAMALLO ASENSIO, S. F., 1989: La ciudad romana de Carthago Noua: la documentación arqueológica, Murcia.

RAMALLO ASENSIO, S.F., 2001: "Sistemas, diseños y motivos en los mosaicos romanos de Carthago Nova : a propósito de los pavimentos de la calle del Duque", $L a$ Casa romana en Carthago Nova. Arquitectura privada y programas decorativos, 169-204, Murcia.

RAMALLO ASENSIO, S. F. y RUIZ VALDERAS, E., 1994: "Un edículo republicano dedicado a Atargatis en Carthago Nova", AEspA, 67, 79-102.

RAMOS FERNÁNDEZ, R., 1974: De Heliké a llici, Alicante.

RAMOS FERNÁNDEZ, R., 1975: La ciudad romana de Illici, Alicante.

RAMOS, R. y UROZ, J., 1992: "“/lici", Conquista romana y modos de intervención en la organización urbana y territorial", Dialoghi di Archeologia, Terza serie, anno 10, 1-2, 95-104.

RAMOS FERNÁNDEZ, R., 1995: El templo ibérico de la Alcudia. La Dama de Elche, Elche.

RAMOS FERNÁNDEZ, R., 1997: "Vestigios cultuales en el templo ibérico de La Alcudia (Elche, Alicante)", Quad. Preh. Arq. Cast., 18, 211-227.

RAMOS FERNÁNDEZ, R., 2003: "Recuerdos de La Alcudia", Las ciudades y los campos de Alicante en época romana, Canelobre, 48, 145-159.

RAMOS FOLQUÉS, A., 1956: "Cerámicas que acompañan a la cerámica pintada de Elche en La Alcudia” , IV Sesión Congreso Internacional de Ciencias Prehistóricas y
Protohistóricas (Madrid 1954), 881 ss.

RAMOS FOLQUÉS, A., 1962: "La Alcudia", E.A.E., 8, Madrid.

RAMOS FOLQUÉS, A., 1966: "Estratigrafia de La Alcudia de Elche", Saitabi, XVI, 71-76.

RAMOS FOLQUÉS, A., 1975: "Un mosaico helenístico en La Alcudia de Elche", A.P.L., XIV, 69-81.

RAMOS. FOLQUÉS, A., 1990: La cerámica ibérica de la Alcudia (Elche, Alicante), Alicante.

RAMOS FOLQUÉS, A. y RAMOS FERNÁNDEZ, R., 1976: "Excavaciones en la Alcudia de Elche durante los años 1968 al 1973", E. A. E., Madrid.

ROS SALA, M. M., 1989: La pervivencia del elemento indigena: la cerámica ibérica, Murcia.

ROTROFF, S.I., 1982: Hellenistic Pottery. Atenian and imported moldmade bow/s, The Athenian Agora XXII, New Yersey.

SALA SELLÉS, F. 1992: La tienda del alfarero del yacimiento de la Alcudia, Alicante.

SALA SELLÉS, F., 1998: "Los problemas de caracterización del siglo III a.C. en los yacimientos de la Contestania", Arqueomediterrània, 4: Les fàcies ceràmiques d'importació a la costa ibérica, les Balears iles Pitiüses durant el segle III a.C. ila primera meitat del segle II a.C., 29-48, Barcelona.

SIEBERT, G., 1978: "Recherches sur les ateliers de bols à reliefs du Péloponnèse", BEFAR 233, Atenas-Paris, Limoges.

SIEBERT, G., 1980: "Les bols a reliefs. Une industrie d'art de l'epoque hellénistique", Céramiques hellénistiques et romaines, 55-83, Paris.

TORDERA GUARINOS, F. F., 1991: "Boles helenisticos en relieve en el poblado de El Monastil", Alebus, 1, 11-32.

VEGAS, M., 1953-1954: "Dos vasos megáricos de Ampurias", Ampurias, XV-XVI, 352-355.

VEGAS, M., 1955-1956: "Fragmento de molde megárico de Ampurias", Ampurias, XVII-XVIII, 252-253. 